\title{
The Relationship between Administrative Corruption and Wages in Egypt's Governmental Sector: An Experimental Analysis
}

\author{
MARWA BILTAGY \\ Cairo University* \\ MERVAT TAHA \\ Cairo University
}

\begin{abstract}
This study investigates the hypothesis that raising wage could reduce administrative corruption. We use experimental methodology applied to 120 participants to test two hypotheses. The first hypothesis is that the higher the wage, the lower the rate of acceptance of bribes (a proxy for corruption), either at zero or positive conviction rates. The second hypothesis is the higher the conviction rate, the lower the rate of acceptance of bribes for both the low-wage and high-wage groups. The main finding of this study is that all obvious differences between wage groups (whether with positive or zero conviction rates) in the acceptance rates of bribes are not significant. This suggests the two hypotheses are not supported
\end{abstract}

Keywords: Administrative Corruption-Experimental Economics-Strategy MethodWages-Institutional Controls.

JEL Classifications: C9, D02, J31.

\section{Introduction}

Many political and economic researchers devote a lot of attention to the phenomenon of corruption, by analyzing the main causes of corruption and developing tools and indicators to measure this phenomenon to better understand corruption and its appropriate treatment. Corruption is a deviation from human instinct (Shabbir and Anwar, 2007). According to Transparency International, corruption is defined as "the abuse of entrusted power for private gain. It can be classified as grand, petty and political, depending on the amounts of money lost and the sector where it occurs". Corruption appears in all sectors of the state, especially the government sector, which is called then "Administrative Corruption".

*Biltagy: Associate Professor; Taha: M.Sc. student; Faculty of Economics and Political Science, Cairo University, Egypt;e-mail: bilmarwa@feps.edu.eg,

(C) 2018 Marwa Biltagy and Mervat Taha . Licensed under the Creative Commons Attribution Noncommercial 3.0 Licence (http://creativecommons.org/licenses/by-nc/3.0/. Available at http: / / rofea.org. 
From the economic perspective, administrative corruption hinders development. The negative effects of administrative corruption include limiting the legitimacy of the Government because of the waste of vast amounts of resources such as time, paid bribes, the use of inefficient human resources through patronage, the use of resources that do not meet the required basic standards. Administrative corruption also involves high transaction costs and thus is an implicit tax. As a result, economic growth is being hampered, and it weakens competitiveness, because rights, services, and goods will favor the rich and the most powerful rather than the most efficient option. It also destroys moral values in society and increases social injustice which has negative impacts on social stability.

Egypt suffers from a high level of administrative corruption, and this is illustrated by Transparency International Corruption Perception Index (CPI) scores that have ranged from 28 to 37 over the period from 1998 to 2016. For the period 2012-2016, Egypt is ranked 108 out of 176 countries. Administrative corruption has involved substantial tangible costs because of wasted resources, social unrest and injustice, which have already produced societal, political and economic repercussions. As a result, combating corruption is a high priority in Egypt.

Recent studies have focused on identifying determinants of corruption and measuring their significance. Empirical studies haven't agreed on the determinants of corruption, and this is due to differences in the significance of determinants from one study to another depending on the independent variables used, and sometimes their significance is influenced by multicollinearity problem between variables or simultaneity problem. Corruption indices that are being used in these studies are derived from the respondents ' perception of corruption and hence don't reflect the real level of corruption.

Economic experiments have become a trendy methodology in recent studies whether using direct response method or strategy method. This new methodology is relied on in policymaking; experimenting with the application of a particular policy to anticipate the reaction of the citizen.

It is also used with the costly trial-and-error approach, in addition to its ability to identify the phenomenon of corruption (Armantier and Boly, 2008). In this context, the use of economic experiments has expanded to analyze the corruption phenomenon. Hence, the economic experiments are used to control the environment surrounding participants and their characteristics to come out with results that reflect the reality of human behavior, besides several other benefits mentioned through the study (Abbink and Monash, 2012), such as:

- The ease of observing the person's behavior in a simulated environment where corruption is being practiced. 


\section{BILTAGY, TAHA Corruption and Wages in Egypt}

- Analysis of the reaction of the participants - whatever roles they play - to various incentives to determine the most efficient anti-corruption methods.

- Eliminating the causality problem through a controlled environment.

- Cost-effectiveness of economic experiments. However, it's unnecessary that their results are valid when they are applied on the ground (Croson, 2003).

According to previous studies, wages are an effective tool for combating corruption. The inverse correlation between corruption and wage level is due to several reasons: higher wages make administrative positions more attractive relative to the private sector. In addition, higher wages increase the moral cost of corruption and reduce incentives for corrupt acts since wages are fairer in that case (Veldhuizen, 2013). And the study of (Abbink, 2002) added that low wages, on the contrary, attract dishonest employees. Abbink and Wu (2017), examine the efficiency of offering rewards for self-reports as a way of fighting bribery.

In this context, some previous studies use an empirical approach and adopt economic experiments, especially the direct response method, and investigate the impact of different wage levels on corruption. However, they do not use the strategy approach. Hence the main contribution of this study to previous literature is to use the strategy method to identify the extent to which a country can combat administrative corruption by raising the level of governmental wages, and whether institutional controls are crucial for that tool to reach its full effectiveness. This study will analyze the impact of wage levels on the rate of acceptance of bribery (a proxy for corruption), with absent institutional controls (zero conviction rate) and with present institutional controls $(0.3 \%$ conviction rate), using the strategy method.

This paper is divided into six sections. Section two covers the literature review, and section three presents the description of the bribery experiment. Afterward, the experimental design and procedures are illustrated in section four followed by the results in section five. Section six concludes.

\section{Literature Review}

Previous studies haven't agreed on the direction of the effect of wages in the government sector on corruption level. Some studies supported the inverse relationship (consistent with the hypothesis of this paper) and yet did not agree on the ideal level of wages sufficient to combat corruption (Muttreja, 2012), (Le Rijckegham and Weder, 1997). They found out that wage increases would reduce the spread of corruption but would not be cost-effective. The study of Borcan et al (2012) also supported the inverse relationship between the two variables without addressing the cost-effectiveness of the policy, noting that the low wages in the Romanian government sector in 2010 has led to higher levels of corruption. In addition, the study of Esmaili et al. (2013) has shown that high wages can indirectly reduce the level of corruption by increasing the overall satisfaction with the job and through motivating the 
employee who feels he is valued by the employer and thus less inclined to carry out corrupt practices. Schulze and Frank (2003) also conducted an experiment to explore the net effect of increasing monitoring on corruption while studying the impact of other factors on corruption such as level of pay in both treatments (zero and positive monitoring rates), and the results include that monitoring decreases overall corruption, and payment doesn't reduce corruption in case of zero monitoring rate (no risk of being caught), while it does so in case of a positive monitoring rate.

Schulze et al., (2013) found a non-linear (U-shaped) relationship between the level of wages in the civil service and the level of perceived corruption. As the relative salary increases, corruption is reduced at low and medium levels of relative salary, up to a certain limit and then corruption increases. This relationship is consistent with the non-linear relationship between the wage level and the effort of the employee.

Other studies, for example Treisman (2000), reject the relationship because of the problem of endogeneity because higher wages can not only reduce corruption but also corrupt officials can use their influence and power to raise their wages as long as no effective means of control and punishment exist.

Despite this difference in the direction of the relationship between corruption and wages, the studies agree that the magnitude and the direction of the impact of the wage level in the government sector on the level of corruption depend on some other factors such as institutional controls. For example, the results of Di Tella \& Schargrodsky (2003) show that without sufficient control, higher relative wages will have a limited impact on reducing levels of corruption.

Besides the previous studies that adopted the empirical methodology, there are other studies that have analyzed corruption using economic experiments method. For example, the study conducted by Veldhuizen (2013) used the direct response approach of the bribery experiment conducted by Abbink et al., (2002) to determine the relationship between corruption and the level of relative wages. It involved the participation of 76 people over four sessions in June 2010 and May 2011. Each session included 25 periods reflecting the longterm relationship between the citizen and the public official. A conviction rate of $0.3 \%$ was used. The results showed that raising the sector wages leads to decreasing corruption levels; high wage employees accepted $38 \%$ of offered bribes on average, while low-wage employees accepted $91 \%$ of offered bribes. The same experiment was conducted with zero conviction rate to analyze the consequence of weakening the institutional controls on corruption level, and the result showed that conviction rate must be positive to have the pursued impact of increasing wages on reducing corruption levels. Friesenbichler et al. (2018) examine the experience of business leaders with government corruption. The authors analyze the factors that determine corruption; the factors related to the respondent i.e. work commitment and the previous experience with the corruption of the respondent. 


\section{BILTAGY, TAHA Corruption and Wages in Egypt}

The study of Jacquemet (2012) used direct response approach of bribery experiment, with the participation of 87 participants over four sessions, 25 periods each, and supported a strong positive correlation between the average level of transfers (Bribes) and the tendency of the employees to accept them. It also showed that the stronger and the more beneficial relationship between the employees and the citizens, the higher the employee's tendency to accept bribes, while the stronger and the more beneficial relationship between the employees and their managers and the more wages are determined with fair criteria, the lower the employee's tendency to accept bribes. These factors determine the direction of wages impact on corruption. While the study of (Abbink, 2002),based on direct response approach and participation of 24 participants with 30 periods in each session, showed that the stronger and the more beneficial relationship between the employees and the citizens, the higher the employee's tendency to accept bribes like the previous study, but a negative relationship between wages and corruption was not supported.

Regarding the external validity of the laboratory experiments tackling the corruption topic, Boly and Armantier (2012) argued their results are reliable and can be generalized because, despite the limited number of studies that examined corruption, their results don't differ significantly from field experiments. In that respect, this study compared several experimental studies and their correspondents in the field studies and results weren't different in most of the compared studies. In addition, tArmantier and Boly (2008) conducted a field and laboratory experiments on bribes and found that, as wages increase, the employee's tendency to accept bribes is reduced, and that enhances the external validity of the laboratory experiments on corruption.

Some laboratory experiments were conducted to analyze other determinants of corruption using direct response approach, for example Drugov et al. (2014) which examined the impact of intermediaries on corruption levels, and accordingly it supported that intermediaries reduce the moral cost of corruption for citizens and employees and reduce the risk borne by both parties due to the lack of a direct connection between the two parties, and hence corruption increases.

Kubbe and McBride (2015) analyzed the characteristics of corrupt people like gender, work experience, time spent away from the country of origin. The experiment included three parties: the citizen, the employee, and the punishment official, and it was found that offering bribes is higher within males compared to females, and it decreases as working experience and the number of years lived abroad are increased.

Regarding the impact of cultural differences on corruption levels, Cameron et al., (2009) studied laboratory experiments in Australia, India, Indonesia, and Singapore to answer that question, and found that Indian participants accepted corruption more often than Australians and that is consistent with the corruption indices results, while Singapore showed higher tendencies to accept bribes than expected, and Indonesia showed lower tendencies than 
expected. Also, Barr and Serra (2010) tested the impact of community values on corruption levels through a laboratory experiment on students in 2005 and repeating it on the same students in 2007 to determine the impact of staying within the British culture on their tendencies to be tolerant with corruption, and found tolerance was lowered in 2007 compared to 2005 .

It's clear that previous studies that used the experimental methodology have relied on the direct response approach to study the impact of wages and other determinants on corruption, while the strategy method was not used in that context, so this paper will use the strategy method to determine the relationship between wages and corruption, and that how this paper will contribute to the literature. In addition, the strategy method provides researchers with the advantage of analyzing the participant's reaction to many bribe levels and each action of the first player, so the participant's strategy is clear and the lowest level of a bribe is determined. The direct response approach analyzes the decisions corresponding to one action of the first player, so experiments may end up without tackling certain nodes. However, the strategy method is criticized by providing a relative abstract environment in the decision-making process compared to the direct response method (Brandts and Charness, 2011).

Regarding the ability to rely on the strategy method, Brandts and Charness (2011) analyzed several studies which compare the behavior by using the strategy method and the direct response method, and found that 16 of 29 studies showed no difference in results, while differences were found in four comparisons, and mixed results were found in the remaining 9 comparisons.

\section{Description of Bribery Experiment}

The current experiment studies the effect of different wage levels on the acceptance rate of bribery (a proxy of corruption level), in two cases: zero conviction rate (the absence of institutional controls), and $0.3 \%$ conviction rate.

The experiment is based on two hypotheses:

1. The higher the wage, the lower the employee's tendency to accept bribes, with high or low conviction rates.

2. As conviction rates increase, reflecting more powerful institutional controls, an employee's tendency to accept bribes decreases with low or high wages.

In this context, two treatments are used: one for low wages and the other for high wages, to determine whether wage levels affect the acceptance rate of bribes. Following Veldhuizen (2013), each of the two treatments is subject to zero and $0.3 \%$ conviction rates to analyze the impact of positive conviction rate on the level of corruption. 


\section{BILTAGY, TAHA Corruption and Wages in Egypt}

The main characteristics of the experiment are:

- The currency used is the experimental point, and the conversion rate is 100 experimental points for one $\mathrm{EGP}^{1}$; such that 1000 experimental points equal to 10 EGP.

- Each participant represents a public official in the experiment, and participants are low wage officials (receive a wage of 1200 experimental points) or high wage officials (receive a wage of 5000 experimental points).

- Each participant receives a payoff at the end of the experiment equal to his wage as a public official plus an additional payment that depends on his/her decision in the experiment.

- The wage group of each participant is randomly chosen, and they are notified of their wage group and wages received by the other group to include the relative wage factor in the experiment.

- The experiment starts with an introduction notifying the participants they are public officials and the wage group they belong to. They are in charge of driver licensing and are asked to provide a license to a citizen who has not passed the driving test. ${ }^{2}$

Two questions are imposed on the participant:

1. Unconditional corruption: whether the participant will give the citizen his license, to measure the general tendency of corruption with no return (bribes).

2. Conditional corruption: 10 levels of bribes will be provided (starting from 200 to 2000 experimental points), and the participant must answer by ACCEPT/REJECT for each bribe level for granting the citizen his license.

The participant is informed that the experiment application will choose randomly ONE bribe level and the participant additional payment will be calculated according to his/her response by ACCEPT or REJECT on the randomly chosen bribe level, so that the participant will think about each bribe level that will affect his payoff. If the bribe level chosen by the experiment application corresponds to REJECT, the payoff will be his wage, and the experiment ends with a questionnaire. If the bribe level chosen by the experiment corresponds to an ACCEPT, the payoff will be his wage plus the bribe level, and the experiment ends with a questionnaire, and this is for zero conviction rate groups.

1 US Dollar = 17.65 EGP (According to Egyptian Central bank, October 2017).

${ }^{2}$ All instructions are illustrated in Appendix 1. 
For $0.3 \%$ conviction rate groups, participants are informed that there is a probability of $0.3 \%$ that the bribe is discovered and the total payoff is lost, so if the bribe level chosen by the experiment application corresponds to an ACCEPT, the experiment application will randomly choose a number from 0 to 999 , if the chosen number is 0 or 1 or 2 , all payoff is lost including the wage and the experiment ends with a questionnaire. If the chosen number for example, is 4, 5 or 998,999 the payoff is preserved as the bribe is not discovered and the experiment ends with a questionnaire. ${ }^{3}$

\section{Experimental Design and Procedures}

The experiment included the participation of 120 participants, who are divided among four groups: L0 low wage group with zero conviction rate, $\mathbf{L 3}$ low wage group with $0.3 \%$ conviction rate, $\mathbf{H 0}$ high wage group with zero conviction rate, $\mathbf{H 3}$ high wage group with $0.3 \%$ conviction rate. Each group included 30 participants.

Students were mainly targeted in the experiment and the sample breaks down as shown in the table (1)

Table 1: Breakdown of the sample

\begin{tabular}{|c|l|l|}
\hline \multirow{2}{*}{ Gender } & Males & $55 \%$ \\
\cline { 2 - 3 } & Females & $45 \%$ \\
\hline \multirow{2}{*}{ Age } & Less than 26 years old & $\begin{array}{l}81 \% \\
\text { with an average age 20.46 years old }\end{array}$ \\
\cline { 2 - 3 } & 26 years old or older & $19 \%$ \\
\hline \multirow{2}{*}{ Profession } & Students or fresh graduates & $61 \%$ \\
\cline { 2 - 3 } & Employees & $39 \%$ \\
& & $\begin{array}{l}76.6 \% \text { of which work in the private sector and } \\
23.4 \% \text { work in the public sector }\end{array}$ \\
\hline
\end{tabular}

Source: Calculated by the authors based on the data derived from the economic experiment.

The participants' fields of study vary; they include economics, political science, engineering, computer engineering, medicine, dentistry, pharmacy, business, law, and languages and translation.

\footnotetext{
${ }^{3}$ Appendices 2 and 3 show screenshots from the experiment related to the two questions and the notes previously described corresponding to different groups to which the participants belong.
} 


\section{BILTAGY, TAHA Corruption and Wages in Egypt}

Regarding the experiment application, a computer programmer was assigned to develop a webpage with the needed specifications of the experiment such as the random selection of bribe levels. The participants register through a web link and it takes 5 to 10 minutes to finish the experiment. The experiment was conducted in the period 1-9 October 2017,

Regarding the compensation, it varied from 14.3 EGP on average for the L3 group to 14.5 EGP for L0 group, and from 51.8 EGP on average for H0 group to 53.3 EGP for H3 group.

The experiment was introduced in Arabic and in English, and it used loaded language that reflects corruption to add reality to the experiment since it was answered online, and especially that the study Abbink, K. \& Hennig-Schmidt, H. (2006) supported no significant difference in results in case of using neutral language (transfer, player 1, etc.) or loaded language (bribe, public official, etc.) through conducting an economic experiment on corruption.

The experiment starts with demographic questions, instructions, decision making questions, and ends up with a questionnaire to determine the participants' opinions about the reasons for making or not making corruption decisions.

\section{Results}

The registration in the experiment required the name, the email, and the phone number of each participant. Then due to the sensitivity of the experiment's topic, it was suggested to enable participants to register with the phone number only, so they could make whatever decisions anonymously without the fear of being known by the researcher. In that regard, the registration process was changed starting from the $32^{\text {nd }}$ participant.

Hence, this section presents the analysis of the whole sample results (120 participants) followed by the analysis of the 89- participant sample results after changing the registration requirements (the sample after excluding the first 31 participants). The questionnaire results will be presented in Appendix 4.

The analysis includes comparisons of acceptance rates of bribes among different groups to test the two hypotheses:

1. As wages increase, the public official has a lower tendency to accept bribes in case of zero or positive conviction rates, and that includes comparisons of acceptance rates of bribes between $\mathrm{L} 0$ and $\mathrm{H} 0$ groups, and between L3 and H3groups.

2. As conviction rate increases, the public official has lower tendency to accept bribes in case of high or low wages, and that includes comparisons of acceptance rates of bribes between $\mathrm{L} 0$ and L3groups, and between $\mathrm{H} 0$ and H3groups.

Afterward, a chi-square test will test the significance and the reliability of the comparisons' results, by calculating the p-values and comparing them to a $5 \%$ significance level. 
From the sample, it was found out that six participants accepted only one random bribe level which is not the highest bribe level. This behavior contradicts with the rational human behavior that implies accepting any bribe level and the subsequent ones until the highest level (2000 experimental points in this case). Hence one interpretation is that these participants misunderstood the experiment. For the analysis, it was assumed that they accepted also all bribe levels greater than the one they chose.

\section{First: The whole sample}

Figure (1) shows the acceptance rate of unconditional corruption: $12.5 \%$ of the sample accepted corruption (i.e., granted the driver's license) without taking bribes. Also, the figure shows the acceptance rate of each level of bribe according to the participants' answers to the second question, which varies from $11.7 \%$ at 200, 400, and 600 experimental points and increases till it reaches $31.7 \%$ at 2000 experimental points. Meanwhile, $68.3 \%$ of the sample did not accept bribes.

Figure 1: Acceptance rate of conditional and unconditional corruption in the total sample

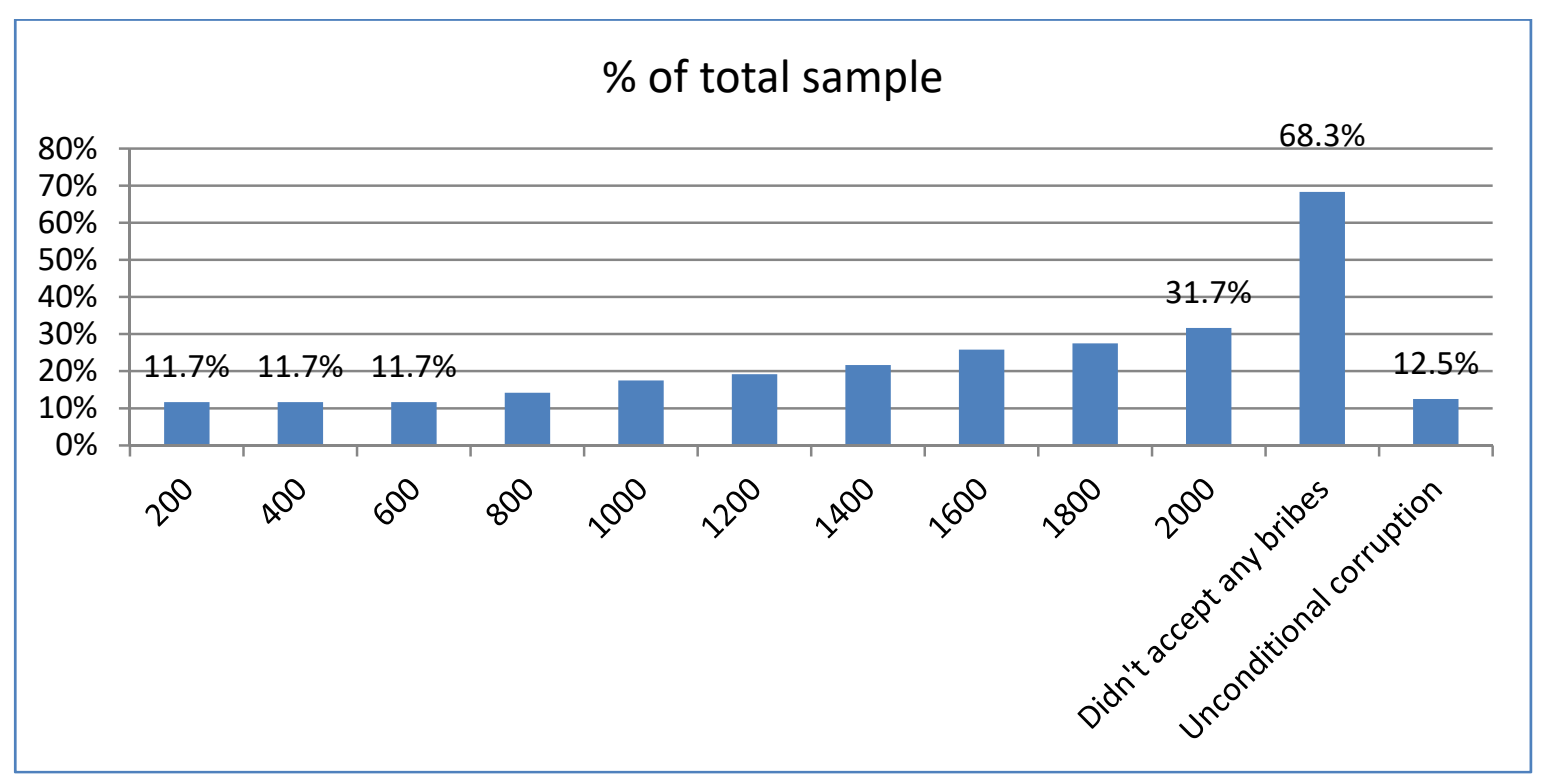

Source: Based on the data derived from the economic experiment.

Despite the low acceptance rate at all bribe levels, the figure shows that the rates increase with increased bribe levels, and table (2) shows the strong positive correlation between the level of bribes and their acceptance rates in the 4 groups, represented by the Spearman 
correlation coefficient, and that result is consistent with the one of the study concerning the positive correlation between the two variables (Jacquemet N., 2012).

Table 2: Spearman correlation coefficient between the levels of bribes and their acceptance rates in the groups

\begin{tabular}{|c|c|c|c|c|}
\hline \multirow{2}{*}{$\rho$} & L0 & L3 & H0 & H3 \\
\cline { 2 - 5 } & 0.972727 & 0.966667 & 0.957576 & 0.981818 \\
\hline
\end{tabular}

Source: Calculated by the authors based on the data derived from the economic experiment.

Figure (2) shows that the percentage of those who did not accept a bribe is lower for L0 group (73.3\%) than $\mathrm{H} 0$ group (76.7\%) and also lower for the L3 group (60\%) than H0 group (63.3\%) which supports the first hypothesis. It is also clear that the percentage of those who accepted no bribe is lower in case of $0.3 \%$ conviction rate compared to zero conviction rate whether among the high wage groups or low wage groups, and that doesn't support the second hypothesis that higher conviction rates imply lower acceptance rates of bribes. Differences in results are suggested to be due to differences in a participant's preferences.

Figure 2: Comparison of the percentages of those who accepted no bribes among the four groups

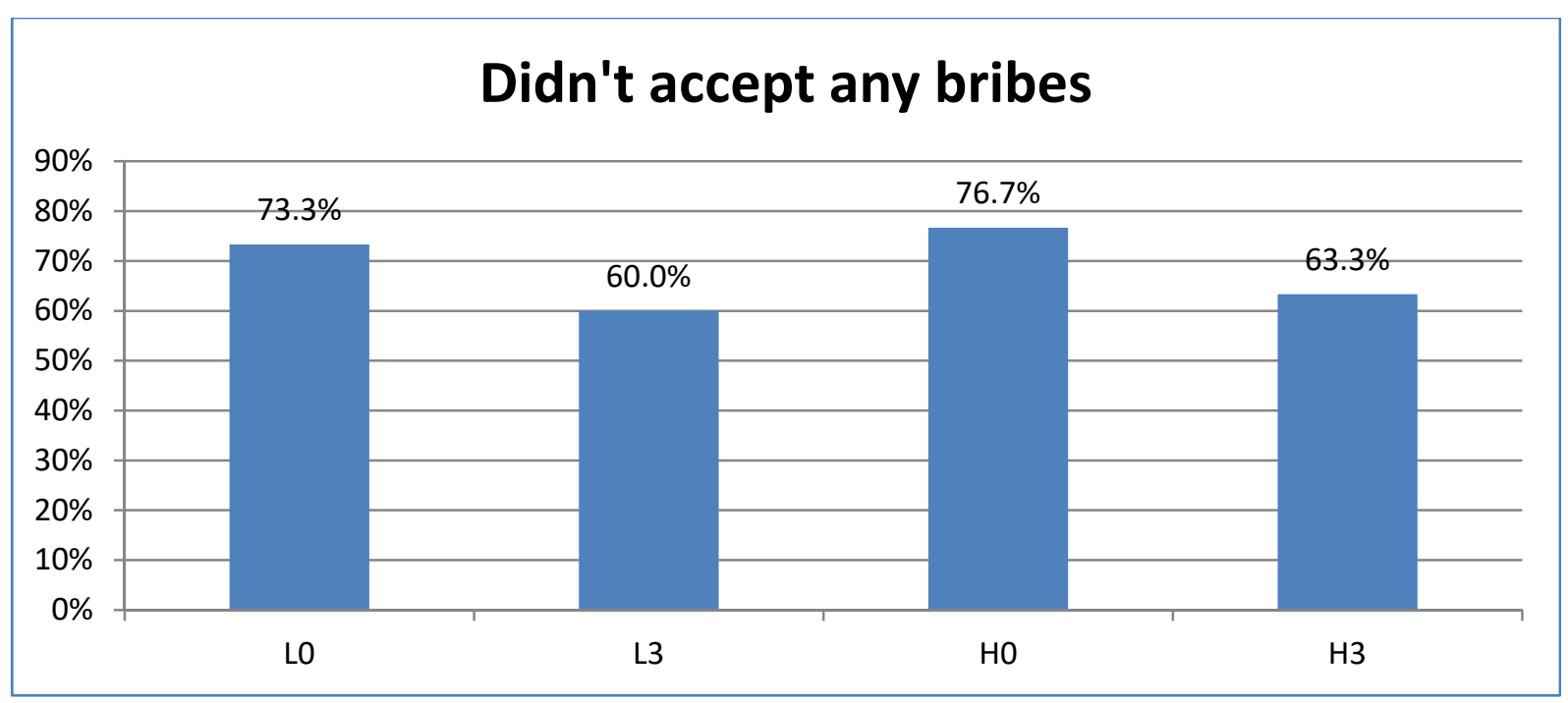

Source: based on the data derived from the economic experiment.

As for the acceptance rates at each bribe level through the answers to the second question, figure(3) shows that the acceptance rates are equal along the first 4 
levels of bribes in groups L0 and $\mathrm{H} 0$, and for the other bribe levels, L0 acceptance rates are higher which supports the first hypothesis. Most rates are equal or higher for H3 group compared to L3 group (except for the last bribe level where L3 is higher than H3) which doesn't support the first hypothesis as shown in figure (4).

Figure 3: Comparison of acceptance rates of bribes at each level in the two groups LO and $\mathrm{HO}$

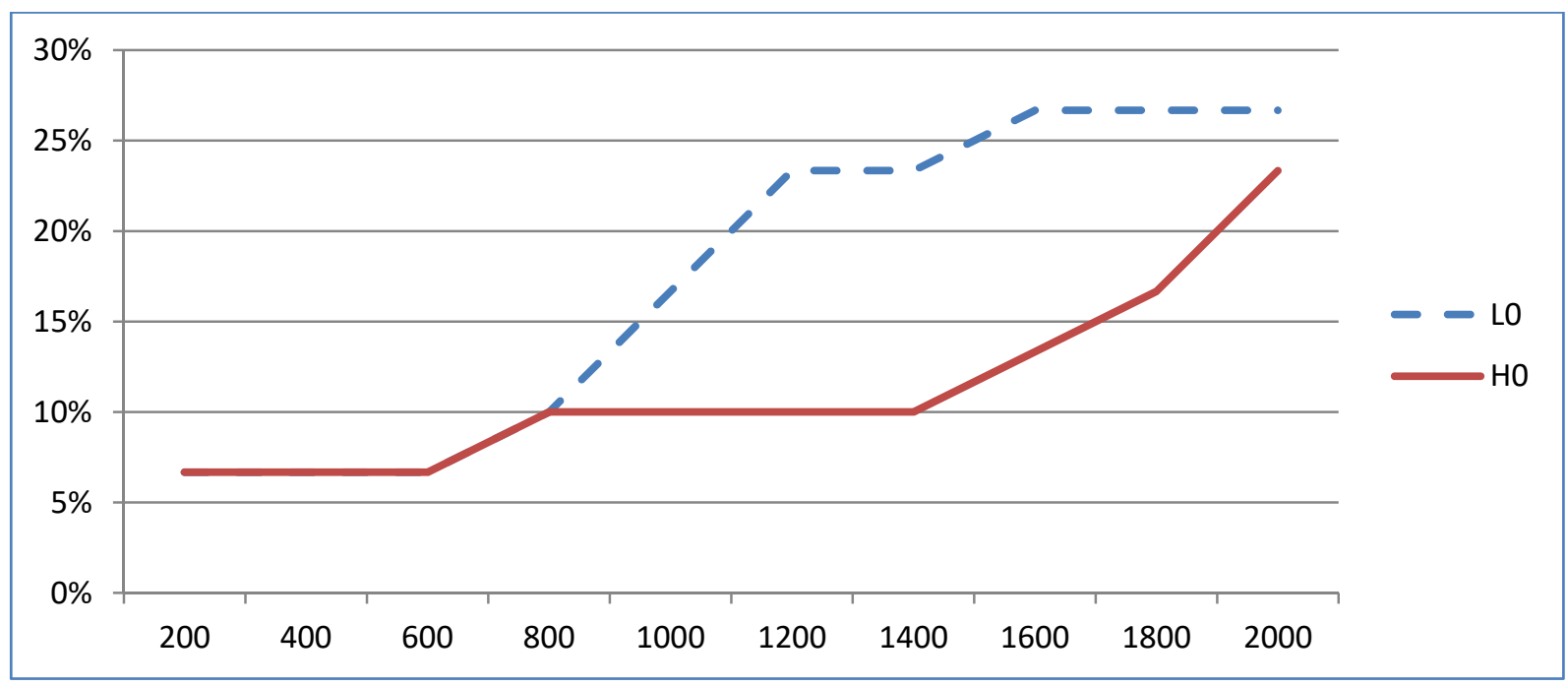

Source: Based on the data derived from the economic experiment.

Figure 4: Comparison of acceptance rates of bribes at each level in the two groups $\mathrm{L} 3$ and $\mathrm{H} 3$

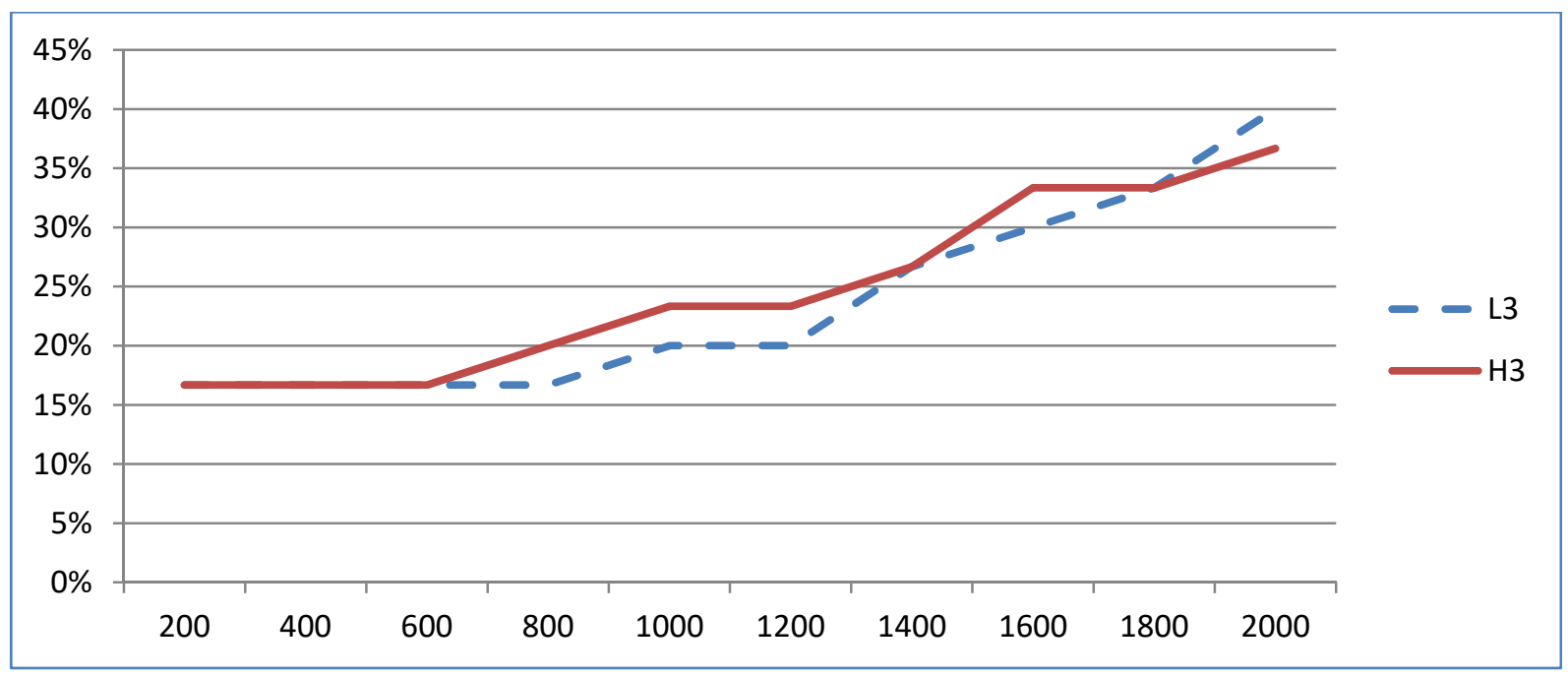




\section{BILTAGY, TAHA Corruption and Wages in Egypt}

Figures (5) and (6) show that the acceptance rate of all bribe levels are higher for groups of $0.3 \%$ conviction rate compared to zero conviction rate for high wage groups and low wage groups (except for 1200 bribe level among the low wage groups), and that doesn't support the second hypothesis.

Figure 5: Comparison of acceptance rates of bribes at each level in the two groups L0 and L3

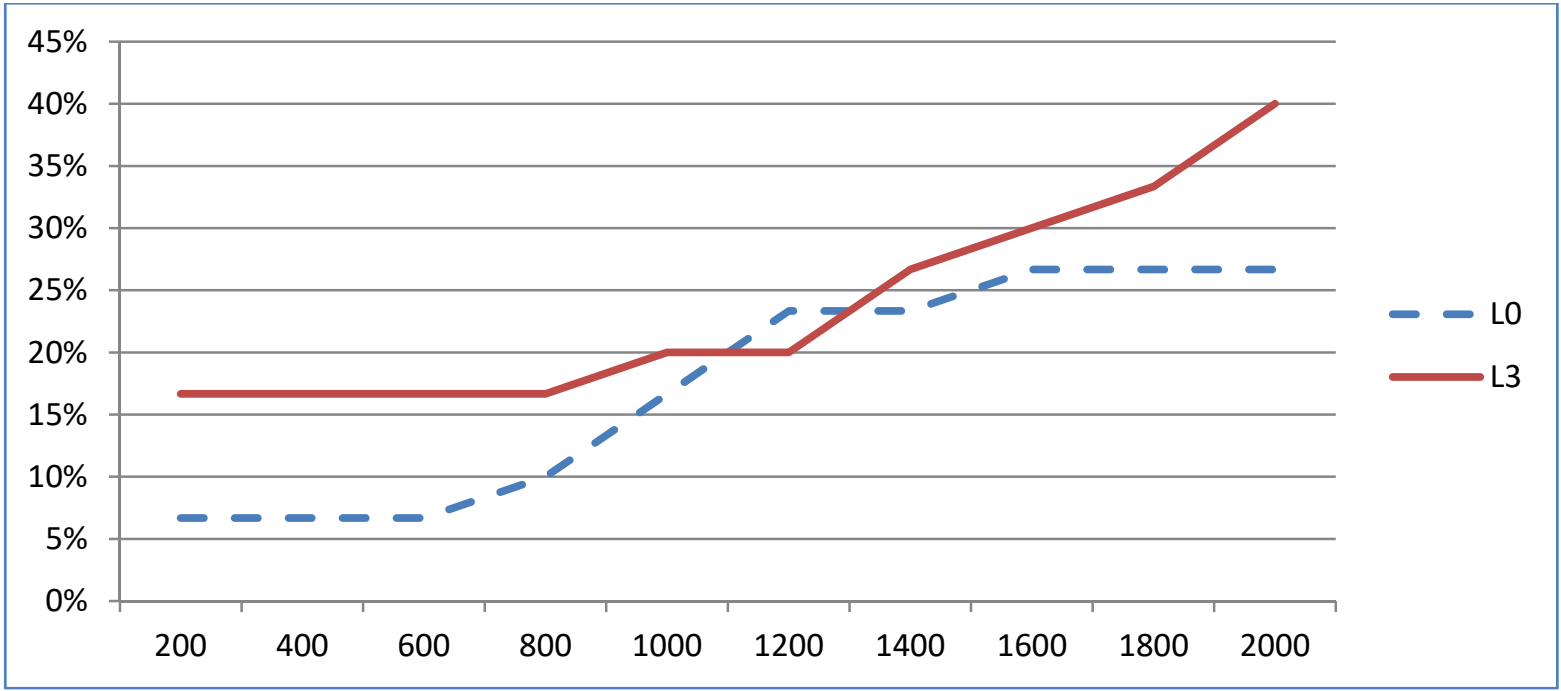

Source: Based on the data derived from the economic experiment.

Figure 6: Comparison of acceptance rates of bribes at each level in the two groups $\mathrm{H} 0$ and $\mathrm{H} 3$

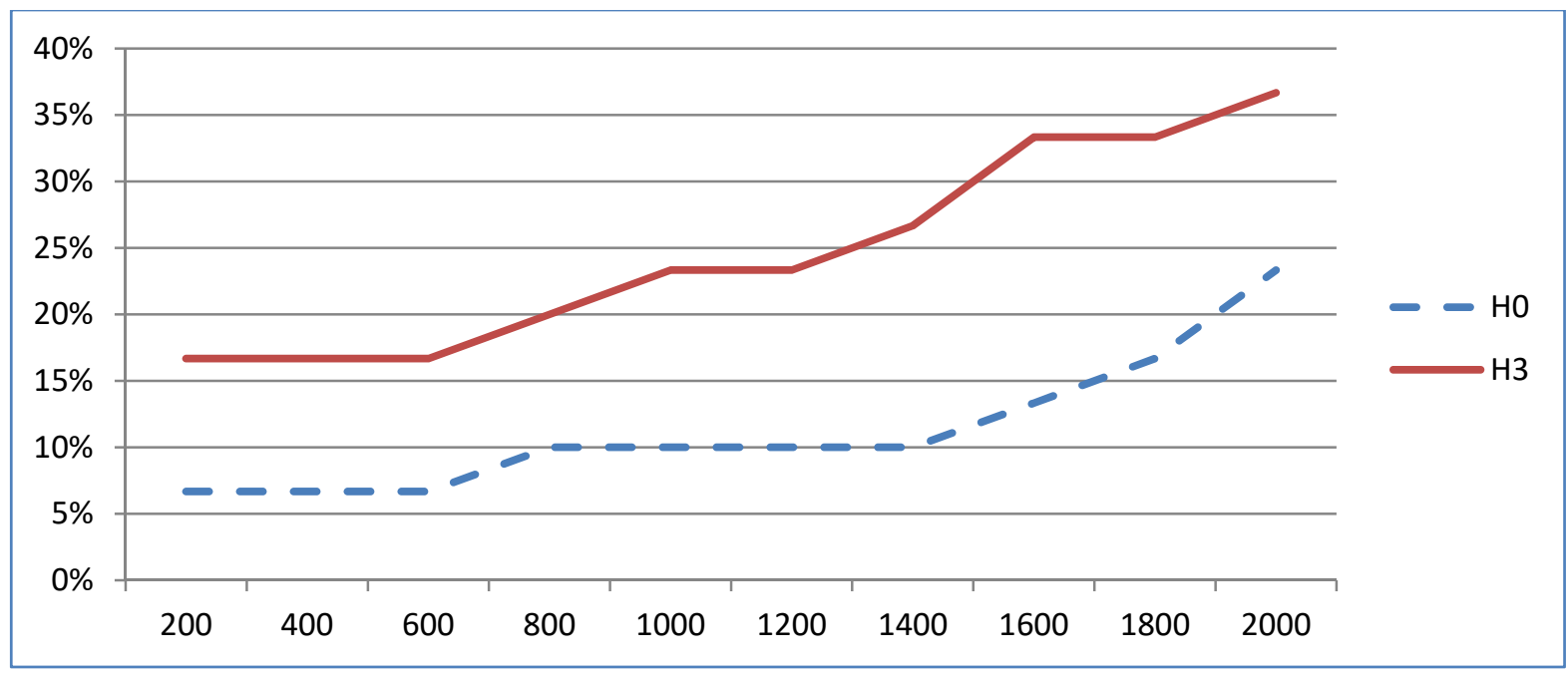


Review of Economic Analysis 10 (2018) 409-447

Table 3: P-value for comparisons between L0 and L3, L0 and H0, H0 and H3, and L3 and H3

\begin{tabular}{|c|c|c|c|c|c|c|c|}
\hline \multicolumn{2}{|c|}{ P-value: L0/L3 } & \multicolumn{2}{|c|}{ P-value: $\mathrm{HO} / \mathrm{H} 3$} & \multicolumn{2}{|c|}{ P-value: $\mathrm{LO} / \mathrm{HO}$} & \multicolumn{2}{|c|}{ P-value: L3/H3 } \\
\hline $200-400$ & $0.088 * *$ & $200-400$ & $0.087975 * *$ & $200-600$ & 1 & 200 & 1 \\
\hline $600-800$ & 0.168 & $600-800$ & 0.107123 & $800-1000$ & 0.56954158 & 400 & 1 \\
\hline 1000 & 0.739 & 1000 & 0.165857 & 1200 & 0.16585666 & 600 & 1 \\
\hline 1200 & 0.754 & 1200 & 0.165857 & 1400 & 0.16585666 & 800 & 0.738649 \\
\hline 1400 & 0.766 & 1400 & $0.095274 * *$ & 1600 & 0.196705602 & 1000 & 0.754001 \\
\hline 1600 & 0.774 & 1600 & $0.06704 * *$ & 1800 & 0.347163802 & 1200 & 0.754001 \\
\hline 1800 & 0.573 & 1800 & 0.136037 & 2000 & 0.765594484 & 1400 & 1 \\
\hline 2000 & 0.273 & 2000 & 0.259796 & $\begin{array}{c}\text { Accepted no } \\
\text { bribes }\end{array}$ & 0.765594484 & 1600 & 0.781375 \\
\hline $\begin{array}{l}\text { Accepted } \\
\text { no bribes }\end{array}$ & 0.273 & $\begin{array}{c}\text { Accepted no } \\
\text { bribes }\end{array}$ & 0.259796 & & & 1800 & 1 \\
\hline & & & & & & 2000 & 0.790602 \\
\hline & & & & & & $\begin{array}{c}\text { Accepted no } \\
\text { bribes }\end{array}$ & 0.790602 \\
\hline
\end{tabular}

Source: Calculated by the authors based on the data derived from the economic experiment.

In the framework of these findings, table (3) shows the p-values calculated based on chisquare test to determine the significance of the previous comparisons' results, either between $\mathrm{L} 0$ and $\mathrm{L} 3$, or $\mathrm{L} 0$ and $\mathrm{H} 0$, or $\mathrm{H} 0$ and $\mathrm{H} 3$, or $\mathrm{L} 3$ and $\mathrm{H} 3$.

It's clear from the previous table that all p-values are higher than the significance level of $5 \%$, except for the bribe levels 200-400 in the L0/L3 comparison, and the bribe levels 200 400,1400 , and 1600 in the $\mathrm{H} 0 / \mathrm{H} 3$ comparison, as the differences are significant at the $10 \%$ significance level, but all differences represented in the previous figures are not significant, hence the two hypotheses are not supported.

The following part will conduct the same analysis, but the first hypothesis will be tested after combining L0 and L3 in one group "L" and combining H0 and H3 in one group "H", and that is based on the previous results of the unsupported second hypothesis that different conviction rates affect corruption level. The second hypothesis will be tested after combining L0 and H0 in one group " $0 \%$ " and combining L3 and H3 in one group " $0.3 \%$ " based on the previous results of the unsupported first hypothesis that different wage levels affect corruption level.

In that context, figure (7) shows that the percentage of those who accepted no bribes are lower in low wage group L (66.7\%) compared to high wage group H (70\%) supporting the first hypothesis. On the other hand, the percentage is higher in the zero conviction rate group (75\%) than the $0.3 \%$ conviction rate group $(61.7 \%)$, and this doesn't support the second hypothesis. 
Figure7: Comparison of the percentages of those who accepted no bribes among the four groups

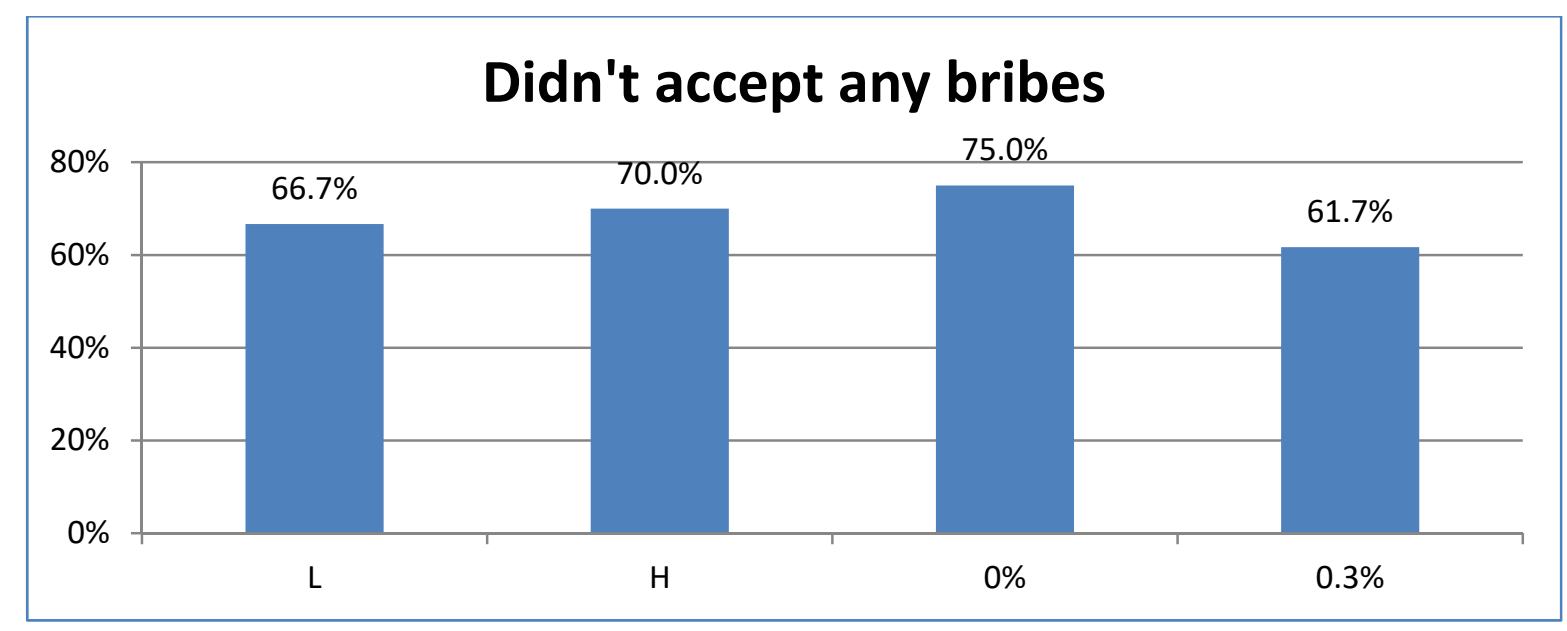

Source: Based on the data derived from the economic experiment.

As for the acceptance rates at each bribe level, higher rates are observed for $\mathrm{L}$ group compared to $\mathrm{H}$ group and that supports the first hypothesis (except for 200 through 800 bribe levels which show either equal rates or higher for $\mathrm{H}$ group), as shown in figure (8).

Figure 8: Comparison of acceptance rates of bribes at each level in the two groups $\mathrm{L}$ and $\mathrm{H}$

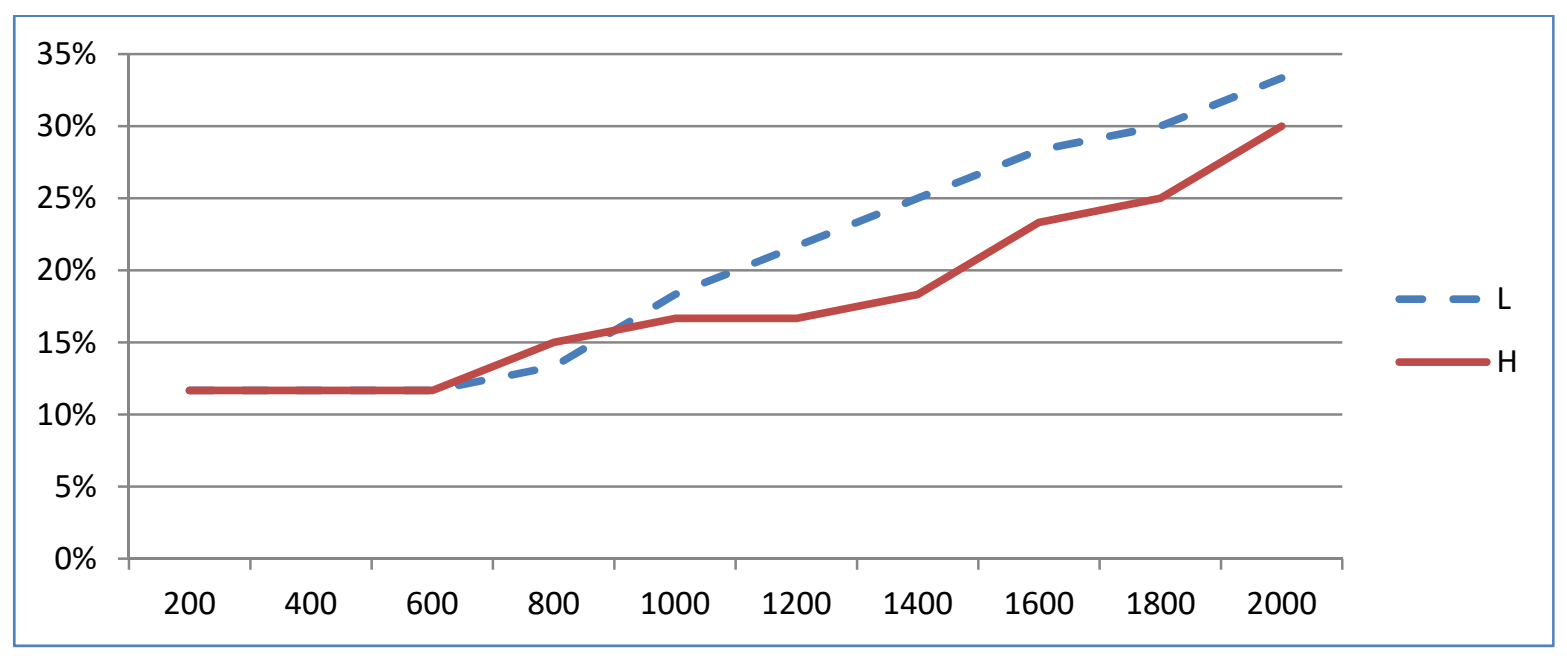

Source: Based on the data derived from the economic experiment. 
Figure 9: Comparison of acceptance rates of bribes at each level in the two groups $0 \%$ and $0.3 \%$

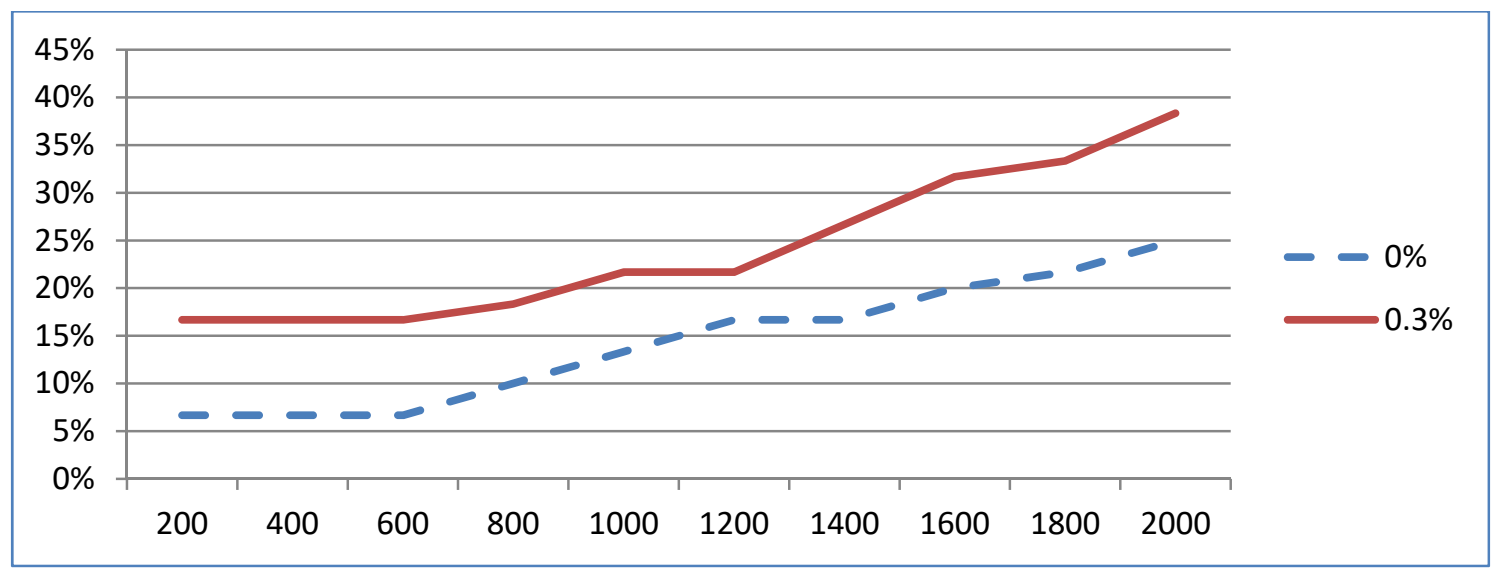

Source: Based on the data derived from the economic experiment.

Figure (9) shows also higher acceptance rates for $0.3 \%$ group compared to $0 \%$ group, thus not supporting the second hypothesis.

According to these findings, table (4) shows the p-values calculated based on chi-square test to determine the significance of the previous comparisons' results, either between $\mathrm{L}$ and $\mathrm{H}$ groups or between $0 \%$ and $0.3 \%$ groups to determine the reliability of the previous results.

Table 4: P-value for comparisons between $\mathrm{L}$ and $\mathrm{H}$ and between $0 \%$ and $0.3 \%$ groups

\begin{tabular}{|c|c|c|}
\hline \multicolumn{3}{|c|}{ P-value } \\
\hline & $\mathrm{L} / \mathrm{H}$ & $0 \% / 0.3 \%$ \\
\hline 200 & 1 & $0.087975^{* *}$ \\
\hline 400 & 1 & $0.087975^{* *}$ \\
\hline 600 & 1 & $0.087975^{* *}$ \\
\hline 800 & 0.793486 & 0.190557 \\
\hline 1000 & 0.810136 & 0.229654 \\
\hline 1200 & 0.486576 & 0.486576 \\
\hline 1400 & 0.375435 & 0.18368 \\
\hline 1600 & 0.53154 & 0.144327 \\
\hline 1800 & 0.539657 & 0.1524 \\
\hline 2000 & 0.694701 & 0.11643 \\
\hline Didn't accept any bribes & 0.694701 & 0.270166 \\
\hline
\end{tabular}

Source: Calculated by the authors based on the data derived from the economic experiment. 


\section{BILTAGY, TAHA Corruption and Wages in Egypt}

It's clear from table (4) that all p-values are higher than significance level of 5\%, implying that all differences represented in the previous figures $(7,8$, and 9) are not significant, except for the bribe levels 200 through 600 in $0 \% / 0.3 \%$ comparison which show significance at $10 \%$ significance level, hence the two hypotheses are not supported even after combining L0 and L3 in one group "L" and combining H0 and H3 in one group " $\mathrm{H}$ " based on the first results of rejected second hypothesis that different conviction rates affect corruption level, and after combining L0 and $\mathrm{H} 0$ in one group " $0 \%$ " and combining L3 and H3 in one group " $0.3 \%$ " based on the first results of rejected first hypothesis that different wage levels affect corruption level.

The following section compares between the whole sample and the sample excluding the responses of the first 31 participants. The name and e-mail were removed as registration requirements starting from the $32^{\text {nd }}$ participant so that participants are encouraged to make their decisions with no sensitivity, especially that the acceptance rates of bribes are higher after excluding the first 31 participants. All analysis is conducted for the 89- participant sample as shown in the following section.

\section{Second: The sample after excluding the first 31 participants}

This sample comprises 89 participants. Each of the groups L3, H0 and H3 has 22 participants, while L0 group includes 23 participants. Figure (10) compares the acceptance rate of conditional and unconditional corruption between the whole sample and the sample after excluding the first 31 participants. The acceptance rates for unconditional corruption and for each bribe level are higher in the sample with 89 participants compared to the whole sample. While percentages of not accepting any bribes are higher for the whole sample compared to the sample with 89 participants. That shows that decisions are affected by the disclosure of the identity and corruption decisions are made more freely, and that fact is an open question that needs to be studied by future experiments.

For the smaller sample, the acceptance rate of unconditional corruption is equal to $15.73 \%$. The rates of acceptance of each bribe level according to the responses of the second question are $14.6 \%$ at 200,400 and 600 , and gradually increase to reach $37.1 \%$ at 2000 bribe level, and $62.9 \%$ of the smaller sample accepted no bribes. Although the acceptance rates are low at all levels, the figure also shows higher acceptance rates corresponding to higher bribe levels, which is the same as for the whole sample.

Figure (11) shows that the percentage of those who accepted no bribes is higher in low wage groups than high wage groups whether at zero or $0.3 \%$ conviction rates, thus supporting the first hypothesis. It is also clear that the percentage of those who accepted no bribe is lower in case of $0.3 \%$ conviction rate compared to zero conviction rate whether among the high wage groups or low wage groups, thus not supporting the second hypothesis that higher 
conviction rates implies lower acceptance rates of bribes, and these are the same results as for the whole sample.

Figure 10: Comparison between the 120 and 89 participants samples regarding the acceptance rates of conditional and unconditional corruption

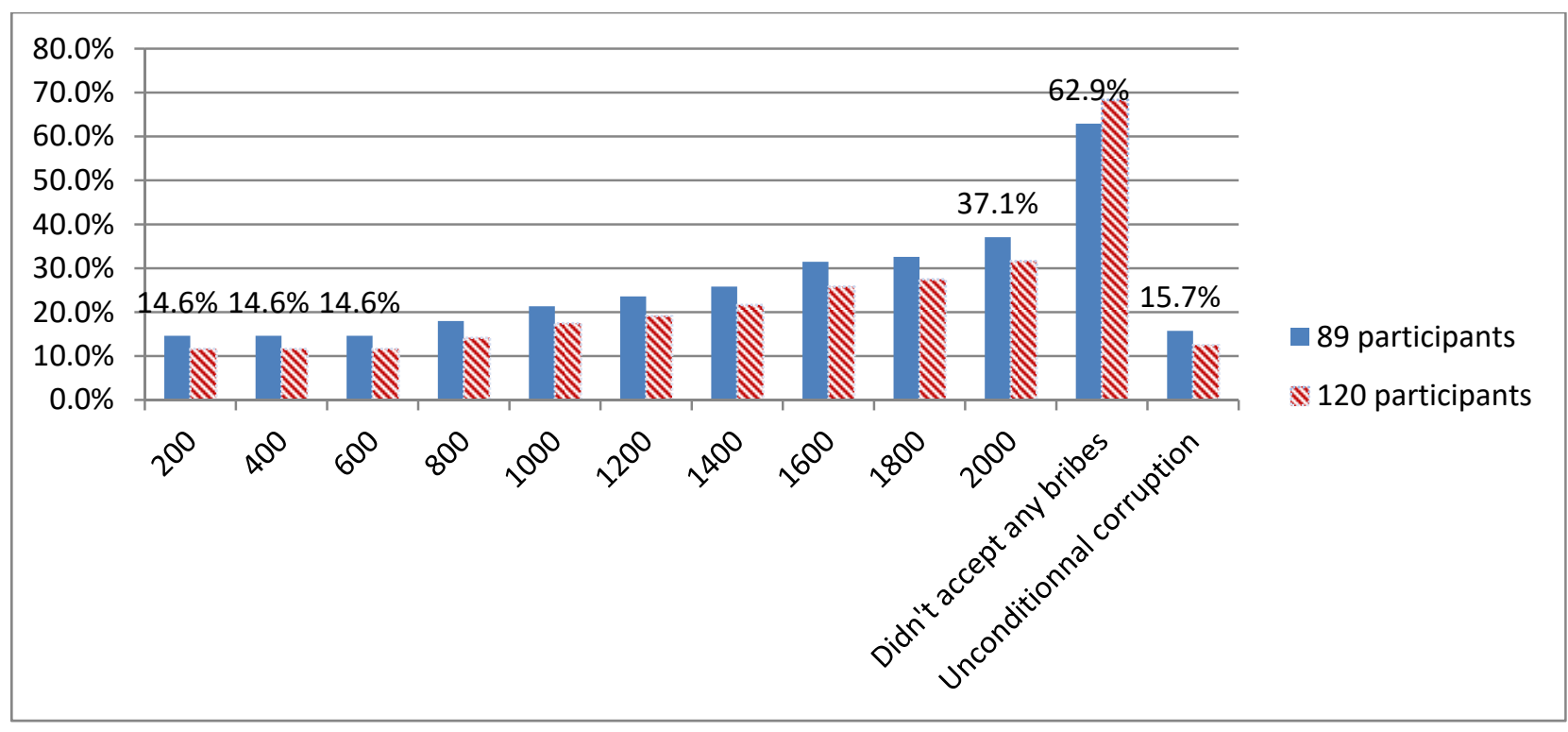

Source: Based on the data derived from the economic experiment.

Figure 11: Comparison of the percentages of those who accepted no bribes among the four groups

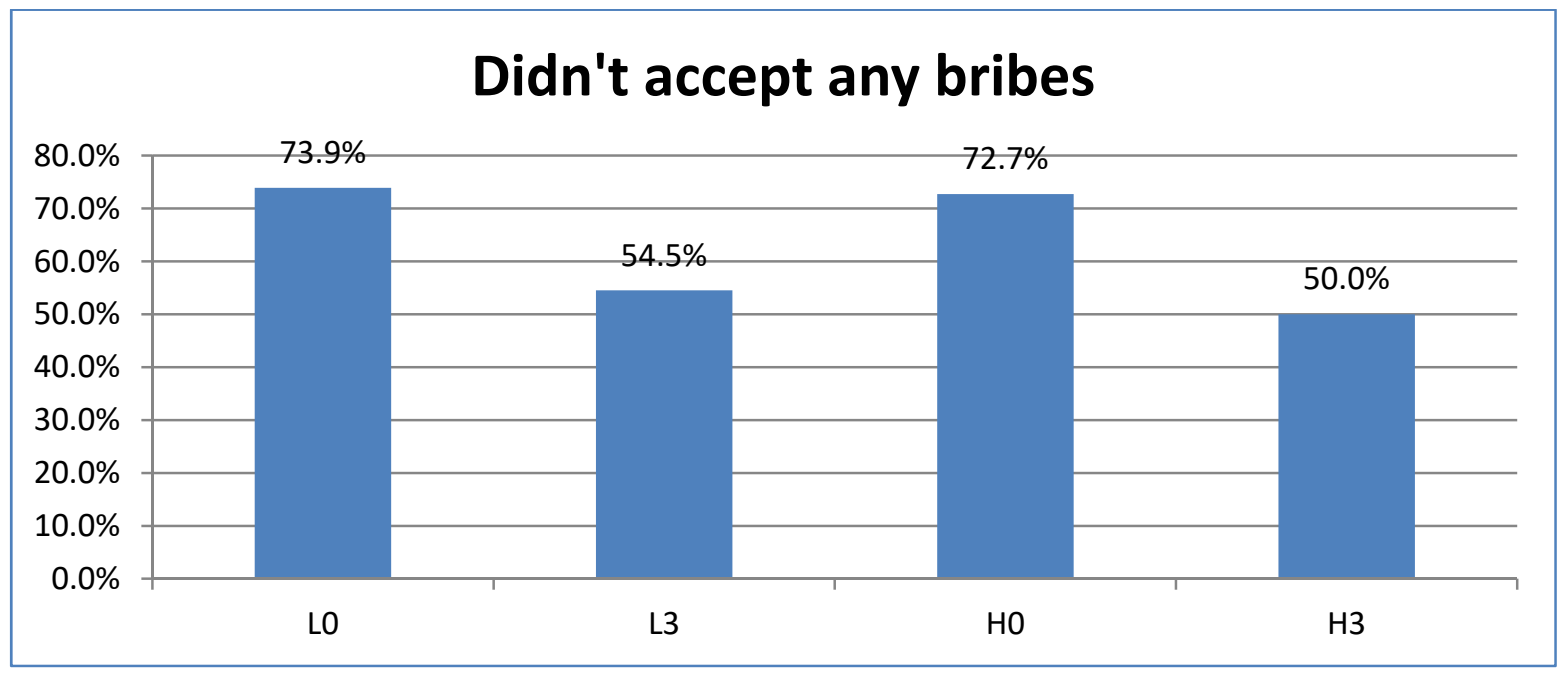

Source: Based on the data derived from the economic experiment. 


\section{BILTAGY, TAHA Corruption and Wages in Egypt}

As for the acceptance rates at each bribe level through the answers to the second question, figure (12) shows that the acceptance rates are lower in L0 than H0 for the first 5 levels of bribes and the last one, and higher in $\mathrm{L} 0$ than $\mathrm{H} 0$ for the following levels of bribes revealing mixed results. All rates are equal or higher for H3 group than the L3 group which doesn't support the first hypothesis as shown in figure (13).

Figure 12: Comparison of acceptance rates of bribes at each level in the two groups $\mathrm{L} 0$ and $\mathrm{H} 0$

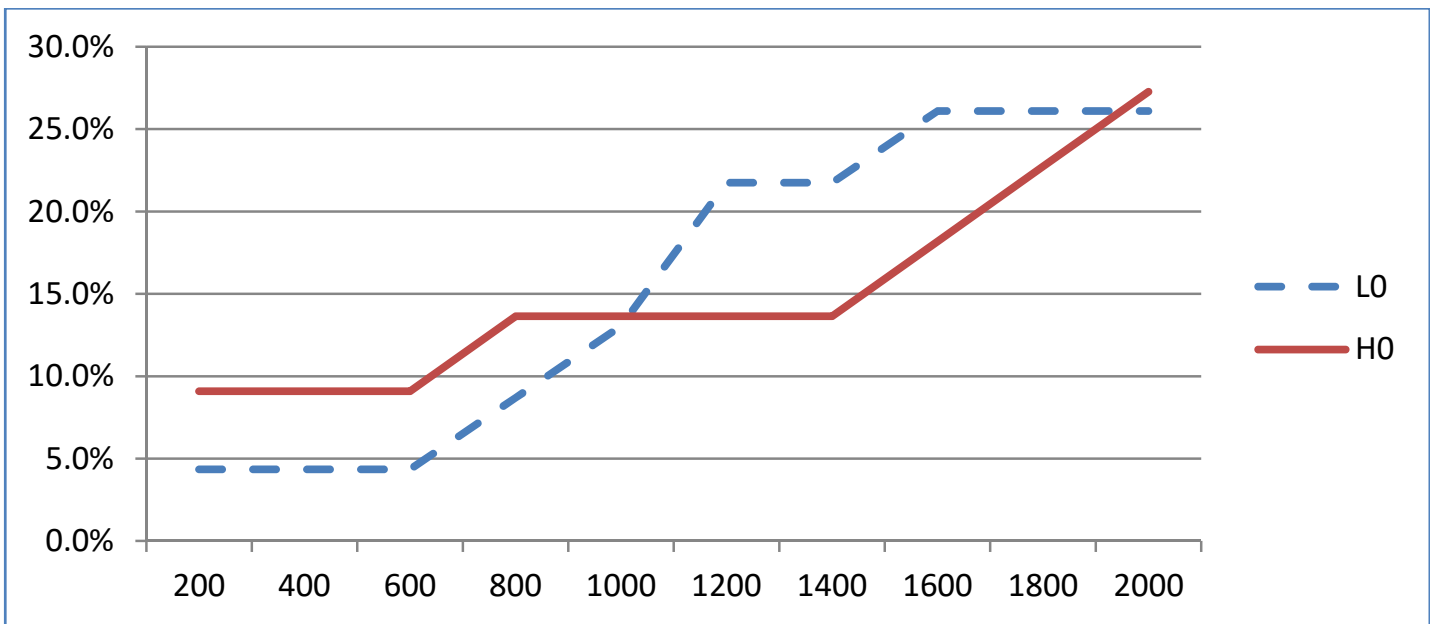

Source: Based on the data derived from the economic experiment.

Figure 13: Comparison of acceptance rates of bribes at each level in the two groups L3 and H3

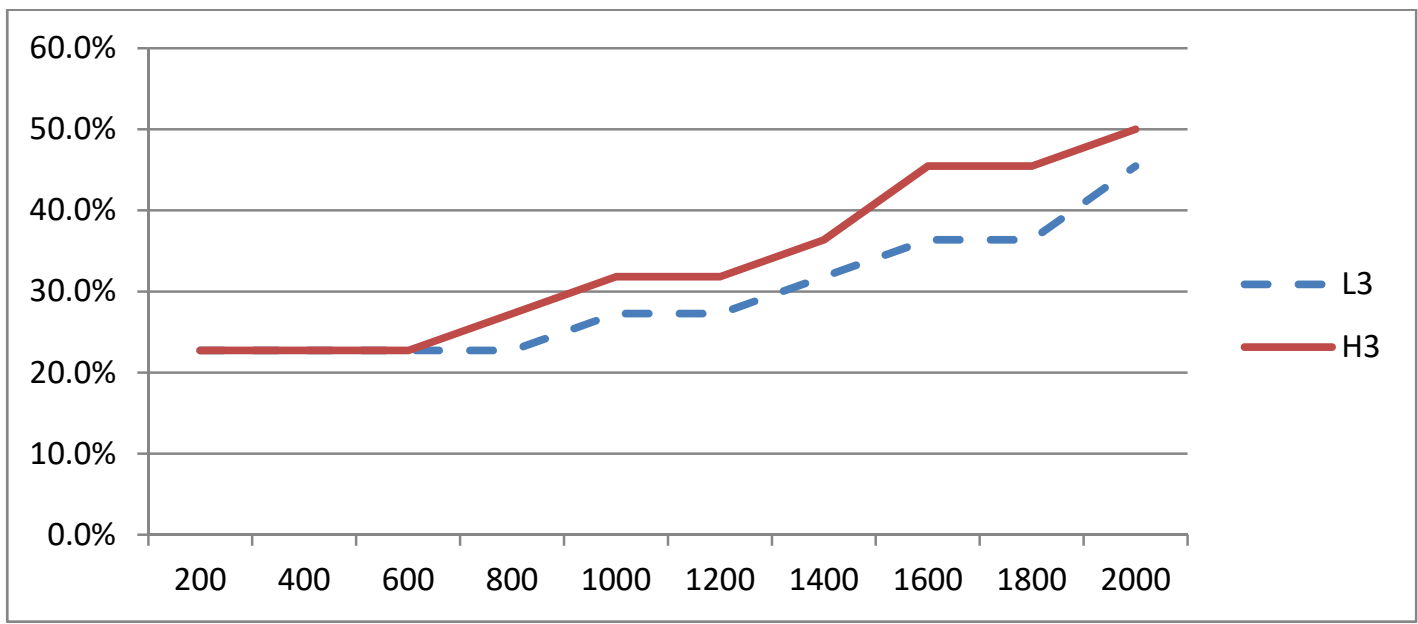

Source: Based on the data derived from the economic experiment. 
Figures (14) and (15) show that the acceptance rate of all bribe levels is higher for groups of $0.3 \%$ conviction rate compared to zero conviction rate for high wage groups and low wage groups, thus not supporting the second hypothesis.

Figure 14: Comparison of acceptance rates of bribes at each level in the two groups L0 and L3

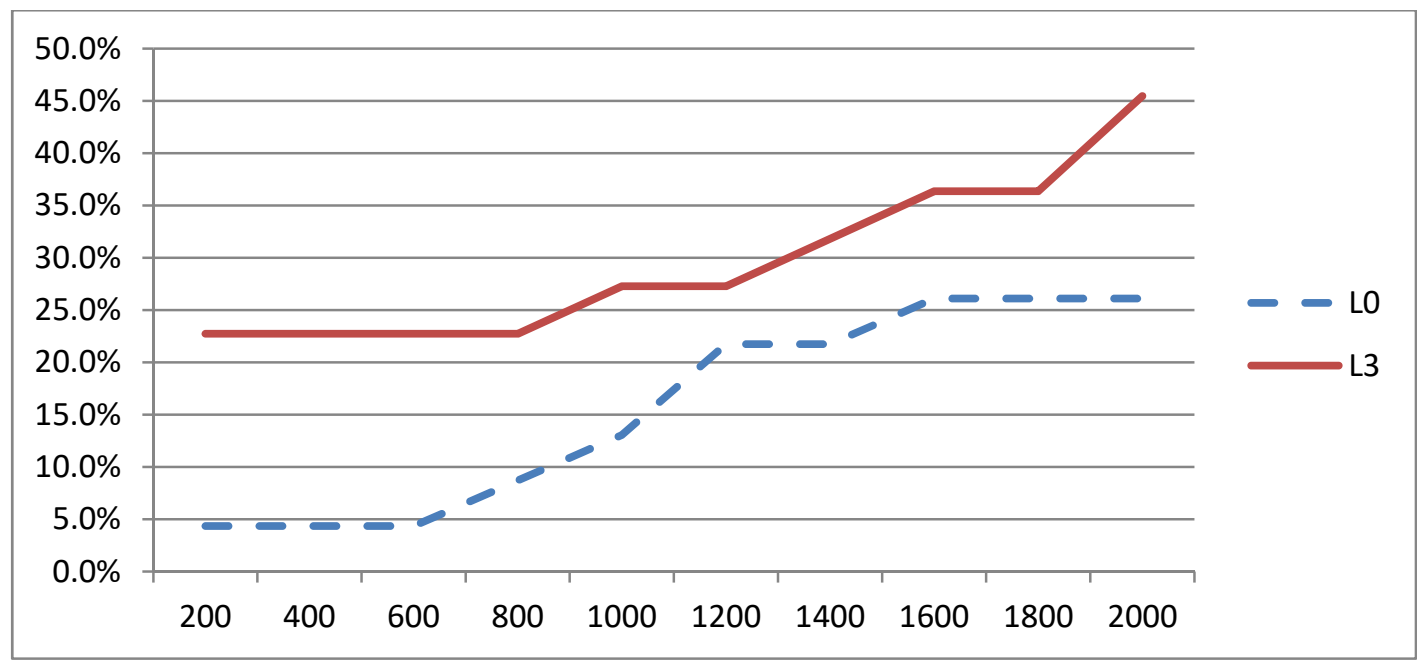

Source: Based on the data derived from the economic experiment.

Figure 15: Comparison of acceptance rates of bribes at each level in the two groups $\mathrm{H} 0$ and $\mathrm{H} 3$

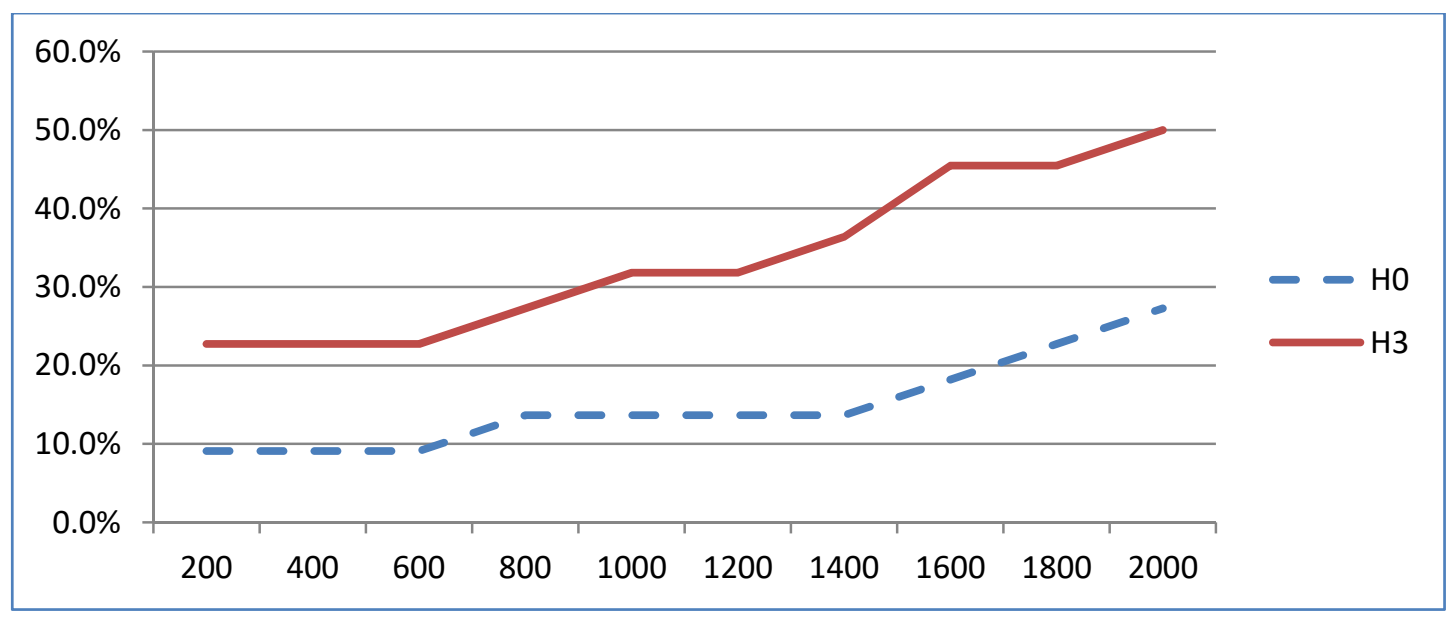

Source: Based on the data derived from the economic experiment. 


\section{BILTAGY, TAHA Corruption and Wages in Egypt}

In the framework of these findings, table (5) shows the p-values calculated based on chisquare test to determine the significance of the previous comparisons' results, either between $\mathrm{L} 0$ and $\mathrm{L} 3$, or $\mathrm{L} 0$ and $\mathrm{H} 0$, or $\mathrm{H} 0$ and $\mathrm{H} 3$, or $\mathrm{L} 3$ and $\mathrm{H} 3$.

Table 5: P-value for comparisons between L0 and L3, L0 and $\mathrm{H} 0, \mathrm{H} 0$ and $\mathrm{H} 3$, and L3 and $\mathrm{H} 3$

\begin{tabular}{|c|c|c|c|c|c|c|c|}
\hline \multicolumn{2}{|c|}{ P-value: L0/L3 } & \multicolumn{2}{|c|}{ P-value: $\mathrm{H} 0 / \mathrm{H} 3$} & \multicolumn{2}{|c|}{ P-value: L0/H0 } & \multicolumn{2}{|c|}{ P-value: $\mathrm{L} 3 / \mathrm{H} 3$} \\
\hline $200-400$ & $0.010347^{*}$ & $200-400$ & $0.08034 * *$ & $200-800$ & 0.230103 & 200 & 1 \\
\hline $600-800$ & $0.028807^{*}$ & $600-800$ & $0.09725 * *$ & $1000-1200$ & 0.623205 & 400 & 1 \\
\hline $1000-1200$ & 0.259679 & 1000 & 0.15016 & $1400-1600$ & 0.342663 & 600 & 1 \\
\hline 1400 & 0.444699 & 1200 & 0.15016 & 1800 & 0.793208 & 800 & 0.727724 \\
\hline 1600 & 0.456652 & 1400 & $0.08172 * *$ & 2000 & 0.928354 & 1000 & 0.741078 \\
\hline 1800 & 0.456652 & 1600 & $0.05214 * *$ & $\begin{array}{c}\text { Accepted no } \\
\text { bribes }\end{array}$ & 0.928354 & 1200 & 0.741078 \\
\hline 2000 & 0.174862 & 1800 & 0.11179 & & & 1400 & 0.750455 \\
\hline $\begin{array}{l}\text { Accepted no } \\
\text { bribes }\end{array}$ & 0.174862 & 2000 & 0.12161 & & & 1600 & 0.539715 \\
\hline & & Accepted no bribes & 0.12161 & & & 1800 & 0.539715 \\
\hline & & & & & & 2000 & 0.762787 \\
\hline & & & & & & $\begin{array}{c}\text { Accepted no } \\
\text { bribes }\end{array}$ & 0.762787 \\
\hline
\end{tabular}

Source: Calculated by the authors based on the data derived from the economic experiment.

It's clear from the table (5) that, all p-values are higher than the significance level of 5\%, except for the bribe levels 200-800 in the L0/L3 comparison. Also, differences in percentages in $\mathrm{H} 0 / \mathrm{H} 3$ are significant at the $10 \%$ significance level for bribe levels $200-800$ and 14001600, which rejects the second hypothesis. And by taking all these results under consideration, differences represented in the previous figures are insignificant; hence the two hypotheses are not supported.

As done within the whole sample analysis, the following part will conduct the same analysis, but the first hypothesis will be tested after combining L0 and L3 in one group "L" and combining $\mathrm{H} 0$ and $\mathrm{H} 3$ in one group " $\mathrm{H}$ ", and that is based on the previous results of rejected second hypothesis that different conviction rates affect corruption level. While the second hypothesis will be tested after combining LO and $\mathrm{HO}$ in one group "0\%" and combining L3 and H3 in one group " $0.3 \%$ " based on the previous results of the rejected first hypothesis that different wage levels affect corruption level.

In that context, figure (16) shows that the percentage of those who didn't accept any bribes are higher in low wage group L (64.4\%) compared to high wage group H (61.4\%), and it's 
also higher in the zero conviction rate group (73.3\%) than the $0.3 \%$ conviction rate group (52.3\%). This implies a contradiction with both hypotheses.

As for the acceptance rates at each bribe level, higher rates are observed for $\mathrm{H}$ group compared to L group (except for 1200and1400 bribe levels which show higher rates for L group) and that still doesn't support the first hypothesis, as shown in figure (17)

Figure 16: Comparison of the percentages of those who accepted no bribes among the four groups

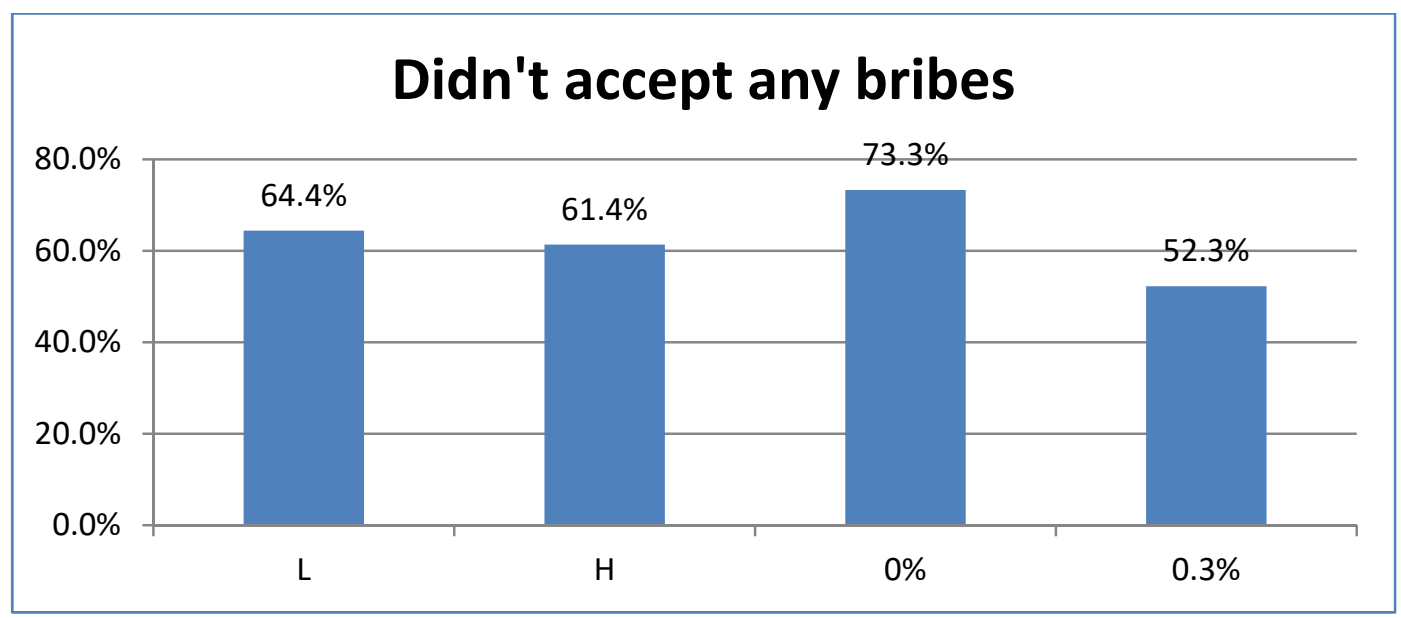

Source: Based on the data derived from the economic experiment.

Figure 17: Comparison of acceptance rates of bribes at each level in the two groups $\mathrm{L}$ and $\mathrm{H}$

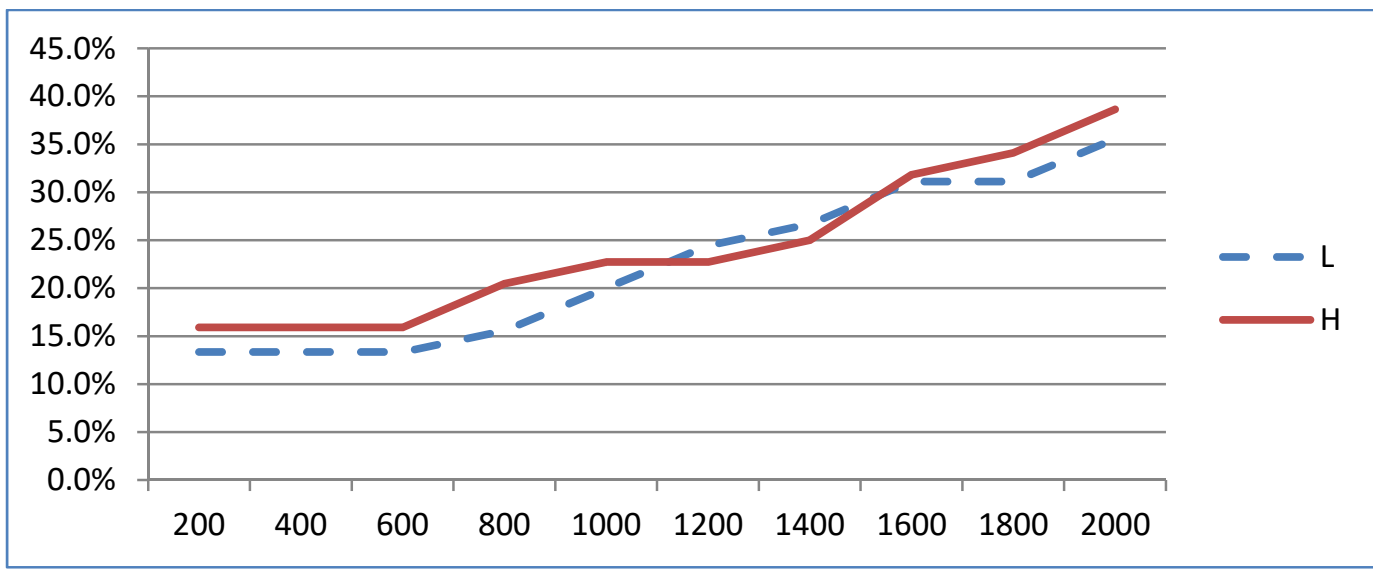

Source: Based on the data derived from the economic experiment. 


\section{BILTAGY, TAHA Corruption and Wages in Egypt}

Figure (18) shows also higher acceptance rates for $0.3 \%$ group compared to $0 \%$ group, thus not supporting the second hypothesis.

According to these findings, table (6) shows the p-values calculated based on chi-square test to determine the significance of the previous comparisons' results, either between $\mathrm{L}$ and $\mathrm{H}$ groups or between $0 \%$ and $0.3 \%$ groups to determine the reliability of the previous results

Figure 18: Comparison of acceptance rates of bribes at each level in the two groups $0 \%$ and $0.3 \%$

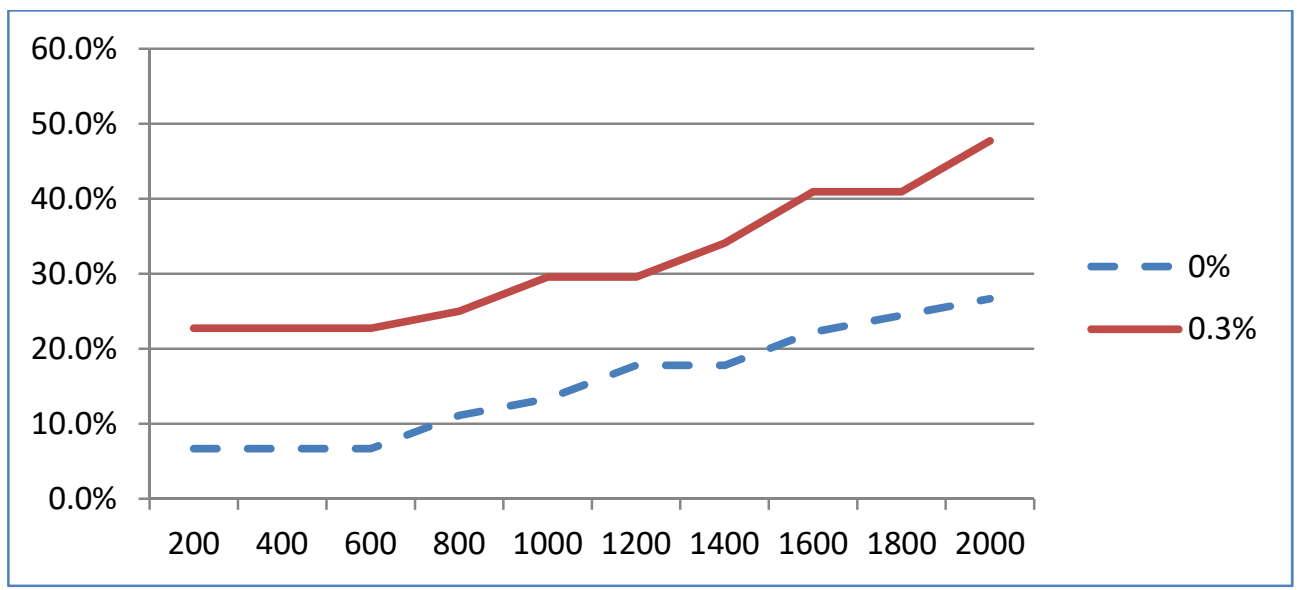

Source: Based on the data derived from the economic experiment.

Table 6: P-value for comparisons between $\mathrm{L}$ and $\mathrm{H}$ and between $0 \%$ and $0.3 \%$ groups

\begin{tabular}{|c|c|c|}
\hline \multicolumn{3}{|c|}{ P-value } \\
\hline & L/H & $0 \% / 0.3 \%$ \\
\hline 200 & 0.730849 & $0.031959^{*}$ \\
\hline 400 & 0.730849 & $0.031959^{*}$ \\
\hline 600 & 0.730849 & $0.031959^{*}$ \\
\hline 800 & 0.547344 & $0.088012^{* *}$ \\
\hline 1000 & 0.753576 & $0.062023^{* *}$ \\
\hline 1200 & 0.848717 & 0.191132 \\
\hline 1400 & 0.857488 & $0.078809^{* *}$ \\
\hline 1600 & 0.942745 & $0.057682^{* *}$ \\
\hline 1800 & 0.764273 & $0.097533^{* *}$ \\
\hline 2000 & 0.763534 & $0.039726^{*}$ \\
\hline Didn't accept any bribes & 0.763534 & $0.039726^{*}$ \\
\hline
\end{tabular}


Table (6) demonstrates that, all p-values are higher than significance level of $5 \%$ for the $\mathrm{L} / \mathrm{H}$ comparison, implying that all differences represented in the previous figures ( 7 and 8$)$ are not significant, hence the first hypothesis is rejected even after combining L0 and L3 in one group "L" and combining $\mathrm{H} 0$ and $\mathrm{H} 3$ in one group " $\mathrm{H}$ " based on the first results of rejected second hypothesis that different conviction rates affect corruption level. Most p-values are lower than $5 \%$ or $10 \%$ significance levels, thus supporting figure 9 ; higher acceptance rates for $0.3 \%$ group compared to $0 \%$ group, and that's after combining L0 and $\mathrm{H} 0$ in one group " $0 \%$ " and combining L3 and H3 in one group " $0.3 \%$ " based on the first results of rejected first hypothesis that different wage levels affect corruption level. This result shows that higher conviction rates lead to a higher corruption level.

It is clear from the previous section, for the whole sample analysis, and for the smaller sample, there is a high rate of non-acceptance of any bribe in the four groups. The previous results also show that the levels of acceptance of the levels of bribery between the four groups are close, despite the large difference between the wages of groups L0 and $\mathrm{H} 0$ and between these groups L3 and H3. As for the second hypothesis, the conviction rate of $0.3 \%$ used by the previous economic experiments may be low when used in the Egyptian example, although the high cost in case of conviction which leads to dismissal of the public official and losing all his/her payoff may matter. But the results implied that this low conviction rate that is not enough to deter corrupt acts because the return from bribes are higher for those who accepted at least one bribe level in the two groups L3 and H3, so the decisions made are probably based on the participants' preferences, norms, and behaviors regardless of the conviction rates.

\section{Conclusion}

Recent studies have relied on economic experiments either by using the direct response method or the strategy method because of the limitations of empirical studies to reflect reality. Economic experiments depend on controlling the environment surrounding the participants and their characteristics to draw conclusions close to the real human behavior, besides other advantages that were mentioned earlier.

In this context, some previous studies that adopted economic experiments approach were presented, especially the direct response method, and we studied the impact of different wage levels on corruption. However, it was found that the strategy approach was not used. Thus, this paper depended on analyzing the impact of wage levels on the rate of acceptance of bribery (a proxy for corruption), with absent institutional controls (zero conviction rate) and with present institutional controls ( $0.3 \%$ conviction rate), using the strategy method.

The results section started with a full sample analysis of 120 participants. A chi-square test was used, and it showed that different acceptance rates of each bribe level among different groups were insignificant, thus rejecting the two hypotheses and that is similar to results of 


\section{BILTAGY, TAHA Corruption and Wages in Egypt}

some previous studies. Based on these findings, the same analysis was conducted again, after combining groups of the same wage together to test the first hypothesis, and groups with the same conviction rates together to test the second hypothesis. The results were insignificant as well.

Then, a comparison was made between the full sample of the 120 participants and the sample after excluding responses of the first 31 participants (the 31 participants were not anonymous in contrast to the following 89 participants). The acceptance rates of all bribe levels were higher in the smaller sample (89 participants) compared with the full sample (120 participants), reflecting the impact of anonymity on the corruption level which is still an open question that needs to be analyzed in further studies.

The same analysis was conducted for the smaller sample and most results rejected the two hypotheses, and combination of groups was redone for the smaller sample and the results were not supporting the first hypothesis, but for the second hypothesis the results showed that higher conviction rates lead to a higher corruption level, which is against the rational human behavior. This finding was similar to that found by the study (Gneezy and Rustichini, 2000), where an experiment was conducted to test the impact of imposing fines on parents who come late to pick up their children from daycare centers in Israel. The latter study found out higher late pickups after imposing that fine, and the authors suggested some reasons for that. First, the fine wasn't severe enough such that parents could tolerate it, and no other worse punishments were expected. Second, the fine reshaped the parents' perceptions of the daycare centers. At first, many parents knew late pickups caused a generous teacher to stay after the normal working hours free of charge, so they tried not to abuse that fact. When fines were imposed, late pickups turned out to be a service with an affordable price (the fine), so they bought that service as much as needed and the internal motivation to come early was suppressed. The second explanation is supported by the study (Frey and Jegen, 2000) which explained that under certain conditions the monetary incentive may suppress the intrinsic motivation to do the right thing which is known as the "Crowding out effect". Hence, as long as the punishment is not high enough compared to the return, the deed subject to the punishment won't be deterred. In the context of the current study, conviction rates that are high enough are required to deter corruption, otherwise, low conviction rates will increase corruption as shown from the experiment's results.

Finally, regarding the insignificance of the experiment results, several reasons have been suggested, which can be considered as limitations of the current study, such as:

- The strategy approach does not allow the participant to repeat the experiment more than once as with direct response experiments, so the answers may not stem from a full understanding of the experiment. 
- The inability of the participants to put themselves in the shoes of the public officials due to the absence of some factors that add realism, such as the absence of the role of the citizen / provider of bribery and relying on the website to do his role by choosing randomly a bribe level, which reduces the realism of the experiment. In addition, externalities didn't have tangible impacts in the experiment; they were only referred to through the introduction for the participant to take them into account.

- One of the common norms in the Egyptian community is to judge and criticize one another, so it is possible that some participants refused bribes fearing being criticized or judged by the researcher.

- $\quad 80 \%$ of the sample represents the ages between 18 and 25 years old, the generation that witnessed the revolution of $25^{\text {th }}$ of January and believed in the values of justice and the fight against corruption; which may have induced participants not to accept bribes.

- Financial constraints led to recruiting small sample size (120 participants) and offering low financial compensations, which may not be considered as sufficient incentives to conduct the experiment and answer honestly. In addition, bribe levels were relatively low with respect to wages, and this was evidenced by $24 \%$ of the participants who chose the low bribe levels as the reason they are rejected, according to question five in the questionnaire, so this finding may be related to the low acceptance rate of bribes in the current experiment. However, it is necessary to point out that some economic experiments show that there is no difference between the results of experiments that rely on small or large financial incentives (Croson, 2003).

- Dependence on low conviction rate $(0.3 \%)$ used by previous economic experiments may not be sufficient when applied in the Egyptian example. The cost of conviction is significant and reflected by the dismissal of the public official and losing all payoff. However, this is not enough to deter corruption because the return on bribery is greater than the risk of losing all, and this finding is for those who have accepted at least one bribe level in L3 and H3 groups, so decisions are based on the participant's own behavior, values, and principles. So the robustness of the experiment's results in higher conviction rates is still an open research question.

Therefore, to enhance the subsequent experiments, it is recommended to conduct the following experiments in the laboratory using the strategy method so that other researchers can easily recruit participants to play the different roles in the corruption process such as the citizen, the public official, and the punishment official. It is also suggested to add other factors that increase the realism of the experiment, especially the externalities. It is of equal importance to find a sponsor to have sufficient funding to increase the size of the sample, raise the financial compensation, and raise the levels of bribes provided. It is also 


\section{BILTAGY, TAHA Corruption and Wages in Egypt}

recommended raise the conviction rate used in the experiment to test the impact of higher conviction rates on corruption levels. Furthermore, it is suggested to assign participants from different age groups and various social and financial classes to the experiment, thus providing the researcher with a heterogeneous sample with different characteristics, and therefore the answers may be different because of different sample backgrounds, which will simulate more accurately the reality of Egyptian society. Finally, and according to the experiment's finding, the impact of anonymity on corruption level may be further studied.

\section{References}

Abbink, K. and H. Hennig-Schmidt. (2006). Neutral versus Loaded Instructions in a Bribery Experiment, Experimental Economics, 9, 103-121.

Abbink, K. and D. Serra. (2012). Anticorruption Policies: Lessons from the Lab. Chap. 4, pages 77- 115 of Serra, Danila, \& Wantchekon, Leonard (eds.), New Advances in Experimental Research on Corruption. Book Series: Research in Experimental Economics. Emerald Group Publishing Limited.

Abbink, K. and K. Wu. (2017). Reward Self-Reporting to Deter Corruption: An Experiment on Mitigating Collusive Bribery. Journal of Economic Behavior and Organization, 133, 256-272.

Abbink, K. (2002). Fair Salaries and the Moral Costs of Corruption. Nottingham: School of Economics, University of Nottingham, University Park.

Armantier, O. and A. Boly. (2008). Can Corruption be Studied in the Lab? Comparing a Field and a Lab Experiment, CIRANO - Scientific Publications No. 2008s-26.

Armantier, O. and A. Boly. (2012). The External Validity of Laboratory Experiments on Corruption, Research in Experimental Economics, 15 (1), 117-144.

Barr, A. and D. Serra. (2010). Corruption and Culture: An Experimental Analysis, Journal of Public Economics, 94, 862-869.

Borcan, O., M. Lindahl, and A. Mitrut. (2012). The Impact of an Unexpected Wage Cut on Corruption: Evidence from a "Xeroxed" Exam, IZA Institute for the Study OF Labor, Discussion Paper No. 6646.

Brandts J. and G. Charness. (2011). The Strategy versus the Direct-Response Method: A First Survey of Experimental Comparisons, Experimental Economics, 14, 375-398.

Cameron, L., A. Chaudhuri, N. Erkal and L. Gangadharan. (2009). Propensities to Engage in and Punish Corrupt Behavior: Experimental Evidence from Australia, India, Indonesia and Singapore, Journal of Public Economics, 93 (7, 8), 843-851.

Casari, M. and T. N. Cason. (2009). The Strategy Method Lowers Measured Trustworthy Behavior, Economics Letters, 103 (3), 157-159.

Croson R. (2003). Why and How to Experiment: Methodologies from Experimental Economics, University Of Illinois Law Review, 921-946. 
Di Tella, R. and E. Schargrodsky. (2003). The Role of Wages and Auditing During a Crackdown on Corruption in the City of Buenos Aires, Journal of Law and Economics, 46(1), 269-292.

Drugov, M., J. Hamman, and D. Serra. (2014). Intermediaries in Corruption: An Experiment, Experimental Economics, 17(1), 78-99.

Esmaili, M., R. Seraji, A. A. Rashid and Z. Bayanloo. (2013). The Impact of Administrative Corruption on HR Productivity (Case Study: Qom University), Advanced Research in Economic and Management Sciences, 11, 246-260.

Frey, B. S., and Jegen, R. (2000). Crowding Theory: A Survey of Empirical Evidence, CESifo Working Paper No. 245.

Friesenbichler, K., Selenko, E. and Clarke, G. (2018). Perceptions of Corruption: An Empirical Study Controlling for Survey Bias, Journal of Interdisciplinary Economics, 30(1), 55-77.

Gneezy, U. and Rustichini, A. (2000). A Fine is a Price, Journal of Legal Studies, 29(1), 1-18.

Kubbe, I. and M. McBride. (2015). An Experimental Study on Corrupt Actions, Center for the Study of Democracy Working Papers.

Muttreja, V. (2012). Effects of Wages of Government Officials on Corruption in Developing Countries, Graduation Thesis, Duke University Durham, North Carolina.

Rijckegham, C. V. and B. Weder. (1997). Corruption and the Rate of Temptation: Do Low Wages in the Civil Service Cause Corruption? IMF Working Paper No.97/73.

Schulze, G. and B. Frank. (2003). Deterrence versus Intrinsic Motivation: Experimental Evidence on the Determinants of Corruptibility, Economics of Governance, 4(2), 143160.

Schulze, G., B. Sjahrir and N. Zakharov. (2013). Corruption in Russia, University of Freiburg, Department of International Economic Policy, Discussion Paper Series No. 22.

Shabbir, G. and M. Anwar. (2007). Determinants of Corruption in Developing Countries, Pakistan Development Review, 46 (4) Part II, 751-764.

Treisman, D. (2000). The Causes of Corruption: A Cross-National Study, Journal of Public Economics, 76, 399-457.

Veldhuizen, R. (2013). The Influence of Wages on Public Officials' Corruptibility: A Laboratory Investigation, Journal of Economic Psychology, 39, 341-356.

\section{Appendix 1: Instruction provided in the experiment}

- You are now taking part in an economics experiment.

- The currency of the experiment is the experimental point. At the end of the experiment, all points you earned will be converted into EGP at a rate of 100 points per EGP, such that 1000 points are worth 10 EGP.

- In this experiment there are two types of public officials: 
BILTAGY, TAHA Corruption and Wages in Egypt

- Low wage public officials with wage 1200 points

- High wage public officials with wage 5000 points

- Your type is randomly chosen.

- You will receive a payment at the end of the experiment equal to your wage besides extra payment that depends on your decisions as illustrated in the experiment.

- To receive your payment, please select the most convenient way:

- Vodafone cash

- Face-to-face meeting

\section{Appendix 2: screenshots from LO experiment}

Screenshot 1: Introduction about the participant and the first question

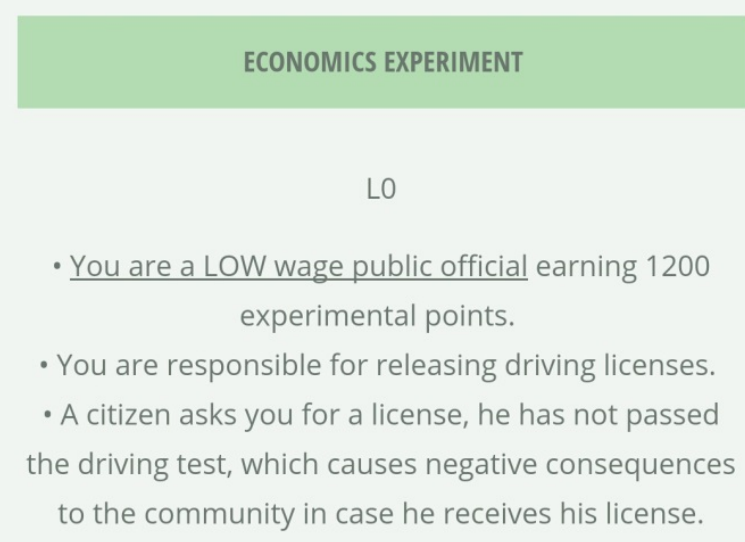

Would you give him the license?

yes no 
Review of Economic Analysis 10 (2018) 409-447

Screenshots $2 \& 3$ : the second question

- The citizen offers you a bribe, please indicate for each of the following bribe levels whether you will ACCEPT or REJECT the bribe to provide the license.

$$
\begin{aligned}
& 200 \\
& \text { accept reject } \\
& 400 \\
& \text { accept } \bigcirc \text { reject } \\
& 600 \\
& \text { accept reject } \\
& 800 \\
& \text { accept reject } \\
& 1000 \\
& \text { accept reject } \\
& 1200 \\
& \text { accept reject } \\
& 1400 \\
& \text { accept reject } \\
& 1600 \\
& \text { accept reject } \\
& 1800 \\
& \text { accept reject } \\
& 2000 \\
& \text { accept reject }
\end{aligned}
$$




\section{BILTAGY, TAHA Corruption and Wages in Egypt}

Screenshot 4: Important notes

**Important notes

All bribes are in points

Choose well your decisions, after submitting your experiment, a bribe level "b" from the above mentioned will be randomly chosen, and according to your decision (ACCEPT or REJECT), your extra payment will be calculated

\section{Example:}

- If b=1400 is randomly chosen out of all bribe levels mentioned above:

* If you answered REJECT to $b=1400$ points, you will receive your wage ONLY of 1200 experimental points.

* If you answered ACCEPT to $b=1400$ points, you will receive the bribe of 1400 experimental points plus your wage of 1200 experimental points. (ie. Total payment $=1400+1200=2600$ experimental points .

\section{NEXT}

\section{Copyright 2017}


Review of Economic Analysis 10 (2018) 409-447

\section{Appendix 3: screenshots from H3 experiment}

Screenshot 1: Introduction about the participant and the first question

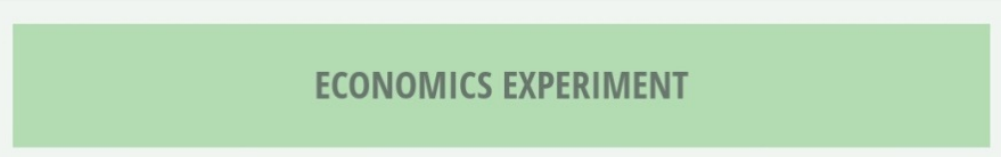

H3

- You are a HIGH wage public official earning 5000

experimental points.

- You are responsible for releasing driving licenses.

- A citizen asks you for a license, he has not passed

the driving test, which causes negative consequences

to the community in case he receives his license.

Would you give him the license?

yes No 


\section{BILTAGY, TAHA Corruption and Wages in Egypt}

\section{Screenshot 2: Important notes}

\section{$\Delta \cdot$}

(1008) 15:36

**Important notes

All bribes are in points

Choose well your decisions, after submitting your experiment, a bribe level "b" from the above mentioned will be randomly chosen, and according to your decision (ACCEPT or REJECT), your extra payment will be calculated

There is a probability of $0.3 \%$ that the bribe is discovered and you will be punished by losing ALL YOUR PAYMENT.

\section{Example:}

- If $b=1400$ is randomly chosen out of all bribe levels mentioned above:

* If you answered REJECT to $b=1400$ points, you will receive your wage ONLY of 5000 experimental points.

* If you answered ACCEPT to $b=1400$ points, this bribe can be discovered with probability $=0.3 \%$. Therefore, a number out of the range from 0 to 999 is randomly drawn by a computer program.

** If the randomly drawn number is 0,1 , or 2 , then the bribe is discovered and you are dismissed from your job and punished by losing ALL YOUR PAYMENT.

** If the randomly drawn number is 3, 4, .., 998, or 999, then the bribe is not discovered, and you will receive the bribe of 1400 experimental points plus your wage of 5000 experimental points. (ie. Total payment $=1400+5000=6400$ experimental points).

\section{NEXT}




\section{Appendix 4: Questionnaire results}

Participants were asked to answer a questionnaire of 8 questions after completing the experiment, and this questionnaire is taken from the study of (Kubbe, Ina, \& McBride, Michael T., 2015), and it aims at identifying participants' views on the causes and deterrents of corruption from the point of view citizen, employee and punishment official. The following section addresses the results of the answers as follows.

\section{Question 1: Have you heard of corruption incidents? If yes, provide details.}

$64 \%$ of the participants have heard of corruption incidents, and they provided examples such as:

- Issuing driving licenses without passing a driving test.

- Paying bribes to get jobs at the government or to have undue privileges, such as tests answers, or to avoid punishment.

- Stalling in finishing governmental procedures in case no bribes are paid.

- Money laundering and unfair price increases on consumers.

- Corruption of public sector employees, police, judiciary, and political people.

- Misuse of influence, power, and nepotism when hiring acquaintances and friends.

- The famous scandal of contaminated blood.

- Corruption in hospitals along with other examples mentioned by the participants.

\section{Question 2: Have you been involved in a corruption incident? If yes, provide details.}

$23 \%$ of the sample was exposed to corruption, and this percentage is not small considering that the average age of most participants doesn't exceed 21 years old. These incidents include several examples as referred by the participants:

- Finishing governmental procedures for driving licenses and pre-marital medical examinations.

- Non-compliance with official working hours.

- Paying bribes to get rid of traffic penalties and to avoid punishment in general.

- Lacking access to services due to refusal to pay bribes, especially for driving licenses.

- Giving priorities to bribe payers or powerful people when providing government services.

- A participant's relative was infected with hepatitis $\mathrm{C}$ because of the transfusion of blood from contaminated blood bags, along with other incidents mentioned by the participants.

The next six questions are multiple-choice questions, and participants must choose at least one answer for each question. 


\section{BILTAGY, TAHA Corruption and Wages in Egypt}

\section{Question 3: Why do you think some citizens don't give bribes?}

Figure (19) illustrates that $77 \%$ of the sample believes that ethics are the strongest deterrent to corruption. The other reasons are close in percentages i.e. $41 \%$ of the sample chose the fear of punishment, $47 \%$ combated corruption, $43 \%$ chose it is unnecessary to make a bribe to get the service, while $39 \%$ of the sample justified that due to costs. Among other reasons, $5 \%$ of the participants added that this is against the interest of the state, or because they do not know how to give bribes without getting discovered, besides religious reasons.

Figure 19: The third question

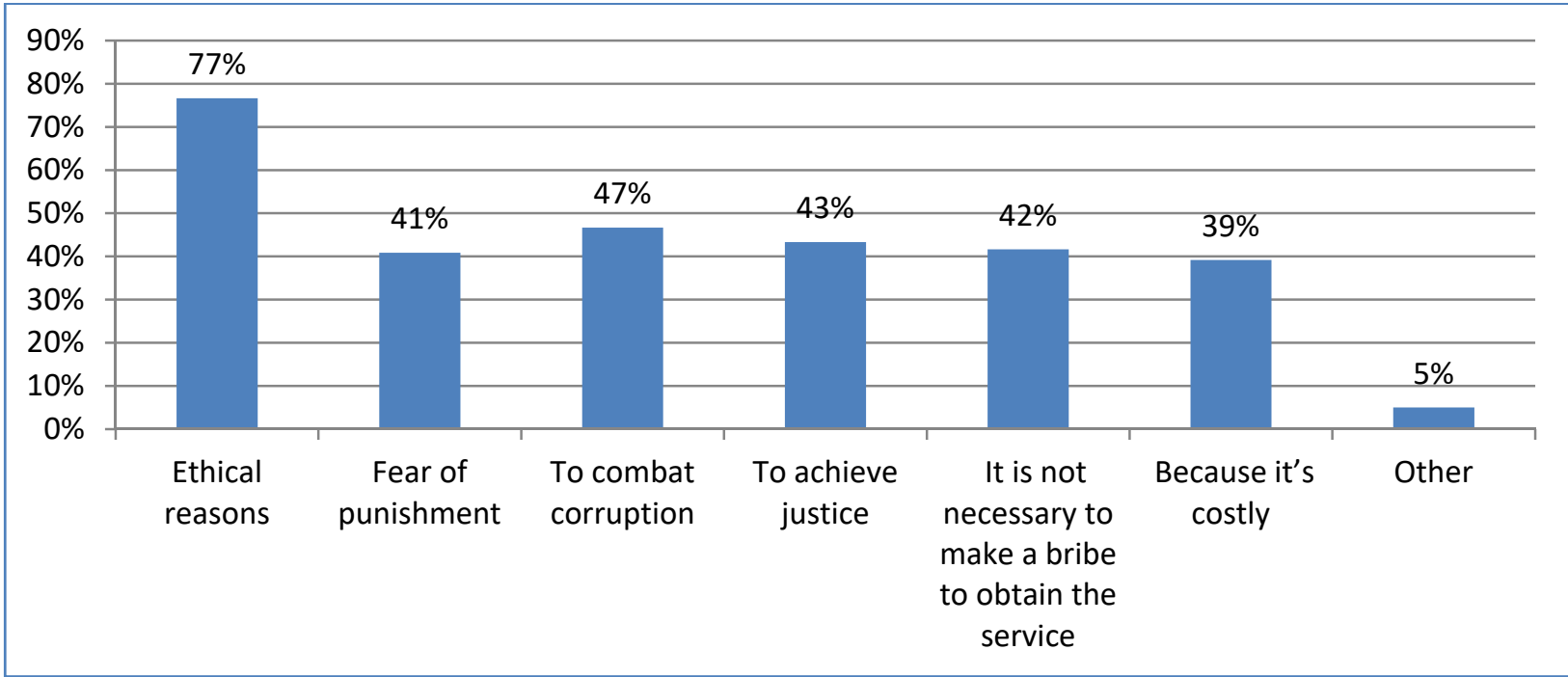

Source: Based on the data derived from the questionnaire answers.

\section{Question 4: Why do you think some citizens are giving bribes?}

In Figure(20), it's clear that $72 \%$ of the participants explained that the biggest cause of corruption of citizens is to gain profits, while $18 \%$ achieved the interests of the state such as raising the wages of citizens and fighting unemployment is the motive of bribing, and $24 \%$ mentioned other reasons such as facilitating procedures, saving time and effort, getting services that are not accomplished without paying bribes, unjustly obtaining services or avoiding punishment, and preferring personal interests to the public interest. All these reasons revolve around the concept of gaining profits. 
Figure 20: The fourth question

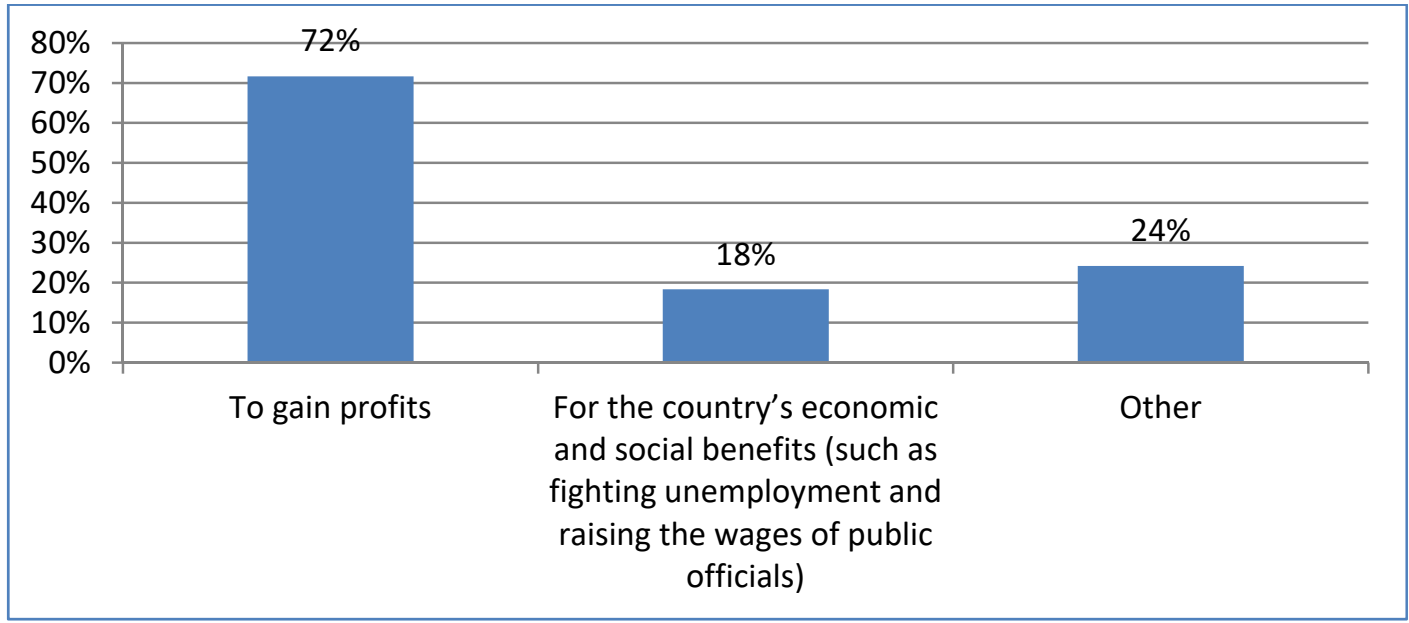

Source: Based on the data derived from the questionnaire answers.

\section{Question 5: Why do you think some public officials do not accept bribes?}

Figure (21) shows that the biggest deterrent for bribe-taking is ethics and fear of punishment with percentages $70 \%$ and $68 \%$ respectively, while $40 \%$ of the participants combated corruption reason, $41 \%$ to achieve justice, and $24 \%$ because of the low bribe levels. The latest result may justify the low acceptance of bribes in the current experiment. Finally, $5 \%$ of the participants added religious reasons, founding a system in the country, and because part of their jobs is to provide services with no extra return as bribes.

Figure 21: The fifth question

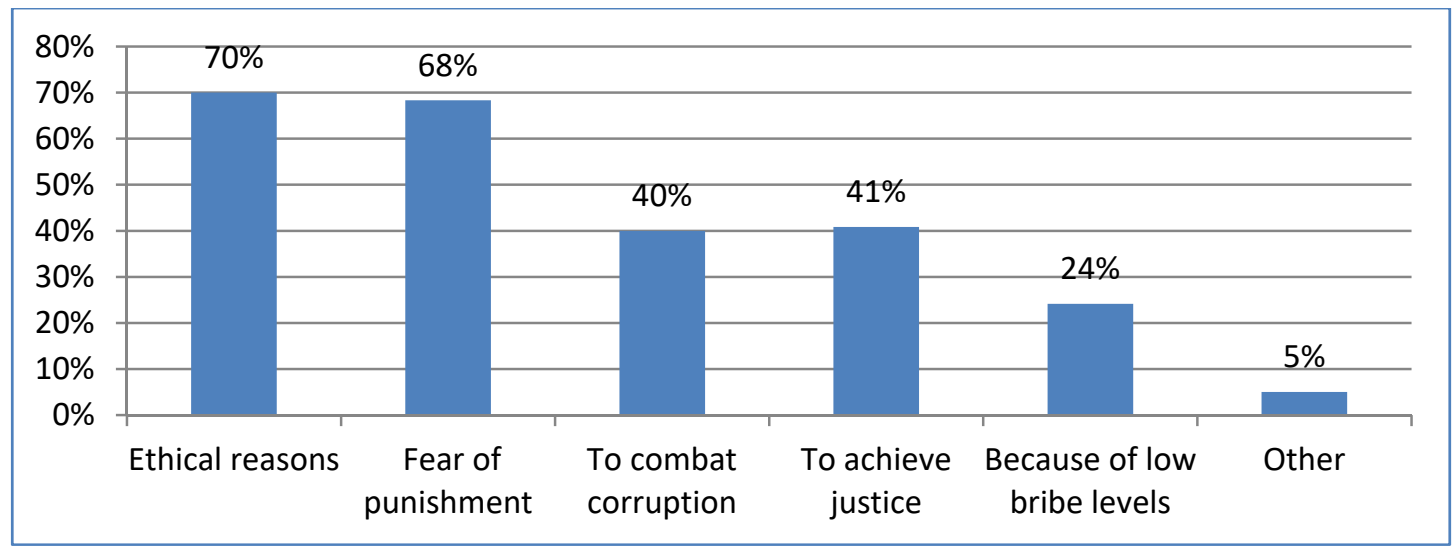

Source: Based on the data derived from the questionnaire answers. 


\section{BILTAGY, TAHA Corruption and Wages in Egypt}

\section{Question 6: Why do you think some public officials accept bribes?}

The percentages are close in explaining the reasons for the acceptance of bribes from the point of view of the public official as shown in Figure (22). The reason for the low level of wages gained $77 \%$ of the participants' opinion, $71 \%$ to gain profits, and $63 \%$ thought inequality in the distribution of wages and wealth in the country is the reason. These results give importance to improving the level of wages in the government sector in the state and achieving justice in the distribution of wealth. Also, from other reasons added by $4 \%$ of the participants are being greedy and seeking personal interests at the expense of public interest and low morals, especially for those with high wages and those reasons revolve also within the framework of the realization of the personal interests.

Figure 22: The sixth Question

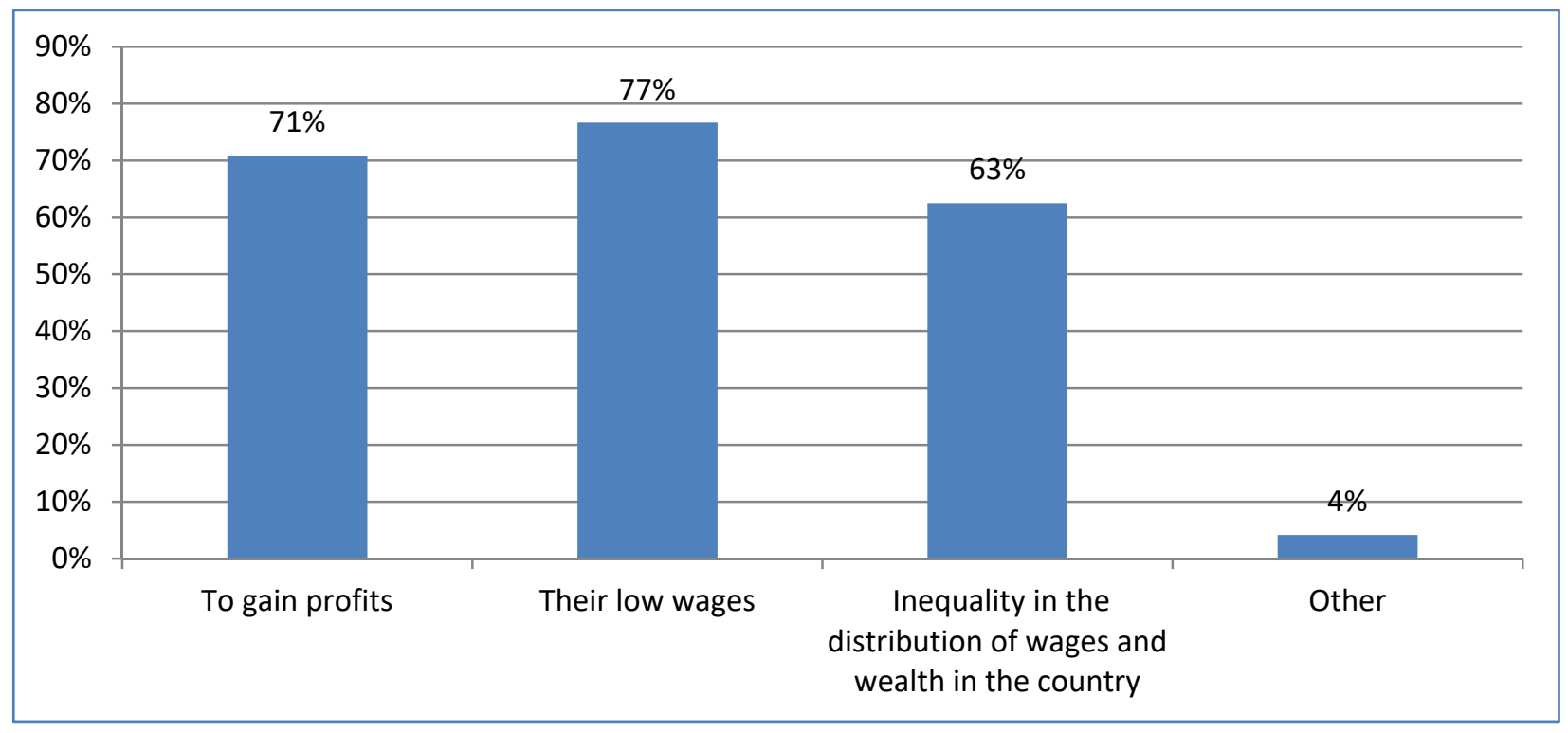

Source: Based on the data derived from the questionnaire answers.

The seventh and eighth questions are imposed to identify the causes and deterrents of corruption among the punishment officials as follows.

\section{Question 7: Why do you think some corruption acts are punished?}

$72 \%, 64 \%$, and $33 \%$ of respondents showed that the imposing punishment was due to the desire to combat corruption, achieve justice and ethical reasons, respectively, as shown in figure (23). Among the other reasons mentioned by $13 \%$ of the sample is the lack of distribution of the benefits of corrupt practices with the punishment officials or other 
stakeholders. Penalties are implemented to achieve certain interests and not to achieve justice and considering it as a random process that applies to the weak (less powerful). Also, this process aims at revealing some false propaganda that justice is being achieved and corruption is being combated, even though corruption is not being combated, so that public opinion is suppressed, and estimates of indicators are maintained at levels that do not affect the local economy and the investment market. These opinions show the mistrust of the public in the punishment system and institutional controls in the country.

Figure 23: The seventh question

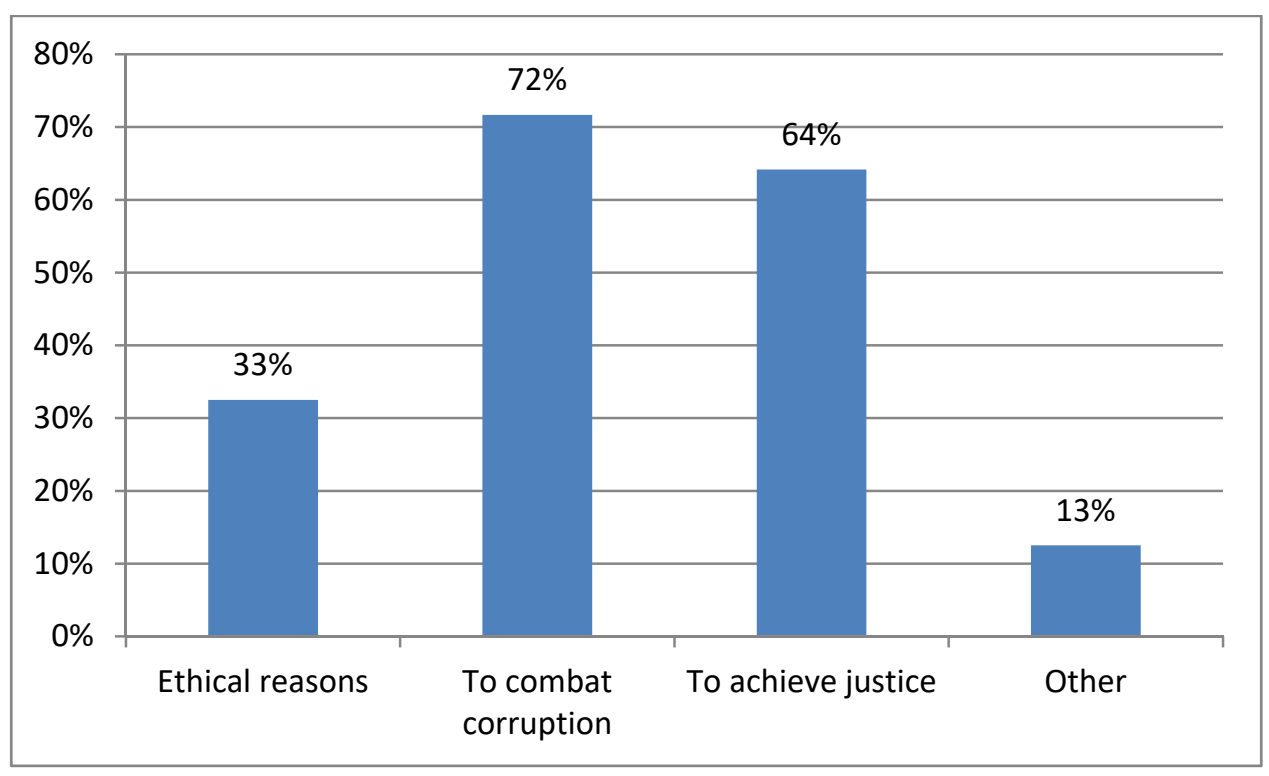

Source: Based on the data derived from the questionnaire answers.

\section{Question 8: Why do you think there is no appropriate punishment for all the corruption acts?}

The inefficiency of punishment systems in the country and the difficulty of their development are at the forefront of the reasons, as explained by $86 \%$ and $51 \%$ of the participants, respectively, in figure (24). While $28 \%$ said the reason is the misconduct of the officials of punishment to do their jobs and their desire to gain profits from corrupt practices. The reason for the need for bribery to achieve justice, for example, was considered as the weakest reason for the absence of punishment for all corruption acts.

Other reasons that $8 \%$ of the participants added included the corruption of the punishment officials themselves and the stakeholders. Therefore, it is not in their interest to reach out an efficient system of punishment, in addition to the small size of entities responsible for 
auditing and controlling government agencies, and the high cost of implementing an effective system of punishment.

Figure 24: The eighth question

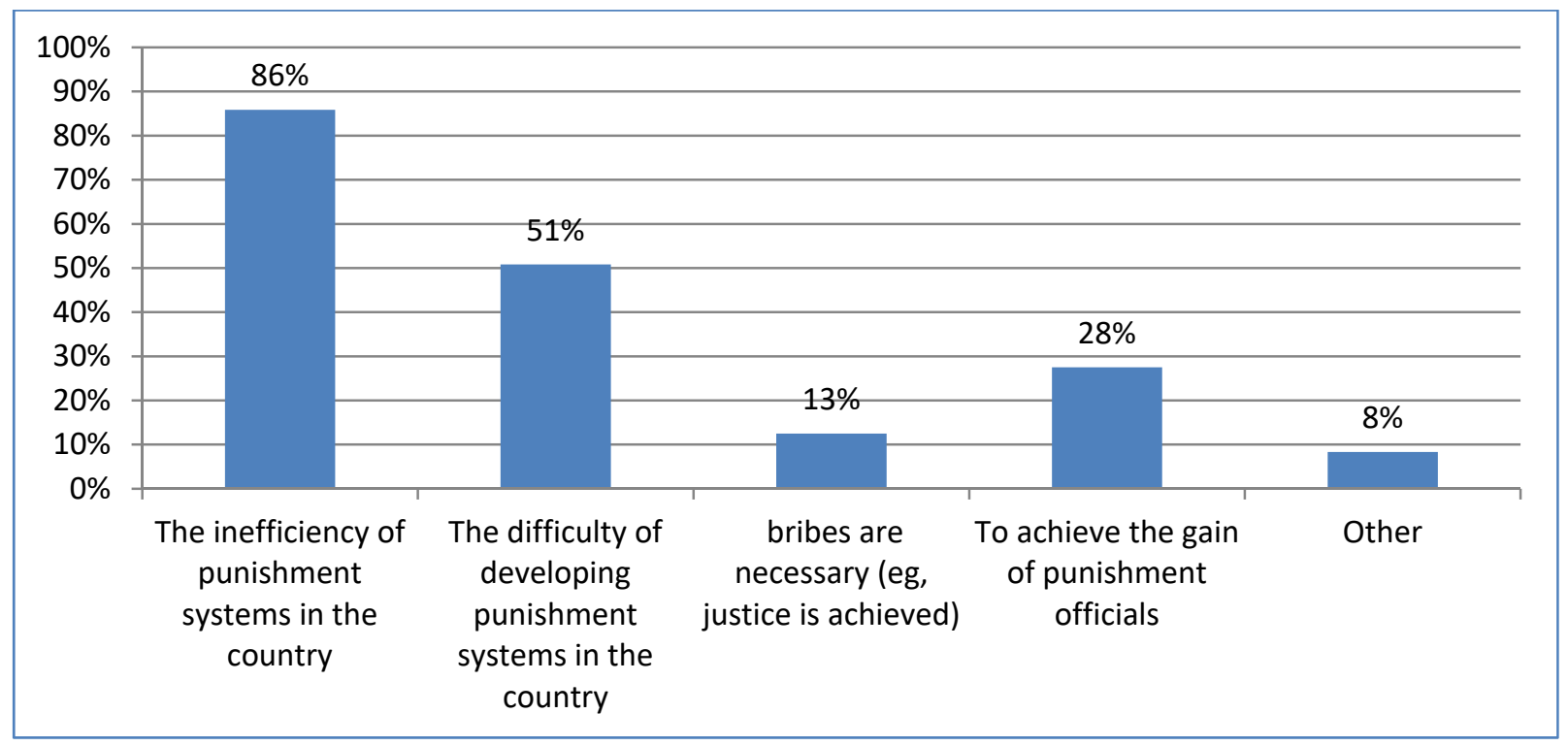

Source: Based on the data derived from the questionnaire answers.

It is clear from the above that the most important results of the questionnaire are the prevalence of corruption, as $64 \%$ of the sample heard of corruption incidents, and $23 \%$ were exposed to corruption. Ethics, the desire to combat corruption, and the fear of punishment are one of the biggest deterrents of corruption, whether for citizens, public officials or punishment officials. This provides an indicator of the need to spread the culture of anticorruption and the preservation of the rights of others along with developing a system of punishment to be deterrent and effective in combating corruption.

From the participants perspectives, the biggest reasons for offering bribes is to gain profits, facilitate procedures, save time and effort, and have access to services that are not done without paying bribes, and that implies the urgency of improving the governmental services and depending more on technology to facilitate the procedures and limit the direct connection of citizens with public officials.

The most important result is that one of the biggest reasons for the acceptance of bribes is the low level of wages and inequality in the distribution of wages and wealth in the country, which shows the importance of giving priority to improving justice and increasing the level of wages in the governmental sector in the state. Moreover, the role of punishment system is crucial. 